\title{
Theoretical study of interaction between aspirine drug and Al-soped graphene nanostructure toward designing of suitable nanocarrier for drug delivery
}

\author{
Sara Farshad ${ }^{1}$ Masoud Darvish Ganii ${ }^{2}$ \\ ${ }^{I}$ Student, Department of Nanochemistry, Faculty of Pharmaceutical Chemistry, Tehran Medical Sciences, Islamic Azad \\ University, Tehran, Iran \\ ${ }^{2}$ Associate Professor, Department of Chemistry, Qaemshahr Branch, Islamic Azad University, Qaemshahr, Iran
}

\begin{abstract}
Background: In recent years, the unique physical and chemical properties of carbon nanostructures has led to many advancements in various fields, including chemistry and pharmaceuticals. Graphene is one of the carbon nanostructures which have attracted significant attention from researchers in adsorption and release of various drugs. Due to the high surface area of graphene, it can be used as a biological carrier in drug delivery. In this study, the interaction of aspirin with a graphene sheet doped with aluminum (graphenealuminum) and possibility of stable complex formation between them were investigated using the theoretical study.

Materials and methods: The performance of carbon nanostructures for adsorption of aspirin on graphenealuminum was evaluated using quantum computation. The calculations were performed using density functional theory modified with dispersion forces (DFT-D) and basic functions by using of ORCA software.

Results: Adsorption energy and electronic structure of aspirin /graphene-aluminum system were calculated. The measured adsorption energy and bond distance were -53.08 ( kcal $/ \mathrm{mol})$ and $1.888 \AA$, respectively. The distribution of electron charge also indicated the continuity of electron clouds between drugs and nanostructure.

Conclusion: The results showed that a strong bond formed between aspirin and graphene-aluminum and the complex formed in the aqueous medium was thermodynamically stable. Regarding the possibility of stable complex formation, graphene-aluminum was expected to be suitable nanocarier for delivery of aspirin to target cells.
\end{abstract}

Keywords: Drug delivery, Aspirin, Graphene doped with aluminum, Energy adsorption, Density functional theory.

Cited as: Farshad S, Darvish Ganji M. Theoretical study of interaction between aspirine drug and Al-soped graphene nanostructure toward desiging of suitable nanocarrier for drug delivery. Medical Science Journal of Islamic Azad University, Tehran Medical Branch 2020; 30(2): 141-154.

Correspondence to: Masoud Darvish Ganji

Tel: +989111137150

E-mail: Ganji_md@yahoo.com

ORCID ID: 0000-0001-8003-9682

Received: 6 Apr 2019; Accepted: 16 Jun 2019 
مجله علوم يزشكى دانشعاه آزاد اسلامى

دوره • r، شماره ץ، تابستان 999، صفحات |f||

Original

Article

\title{
مطالعه نظرى برهمكنش بين داروى آسييرين و نانوساختار گرافنى آلائيده با آلومينيم براى طراحى نانوحامل مناسب براى رسانش دارو
}

\author{
سارا فرشاد'، مسعود درويش تنجى
}

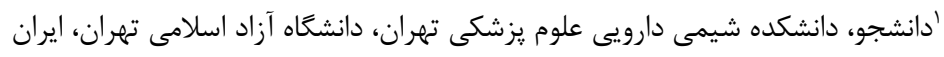

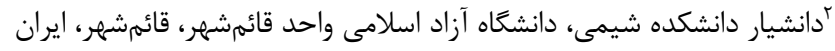

جكيده

سابقه و هدف: خواص منحصر به فرد فيزيكى و شيميا يیى نانوساختارهاى كربنى در سال هاى اخير باعث بيشرفتهاى زئى زيادى در

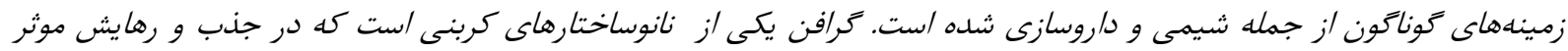

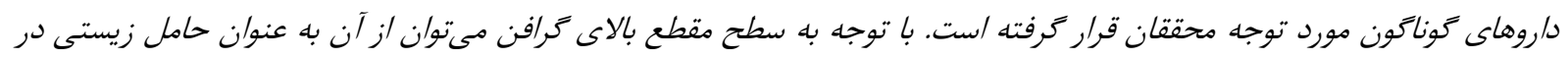

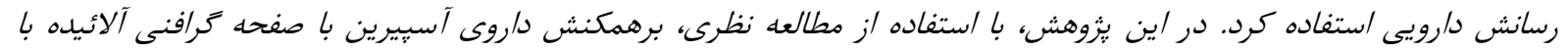

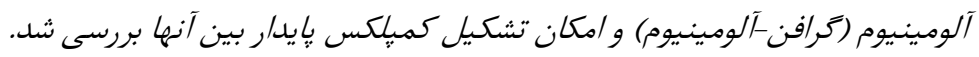

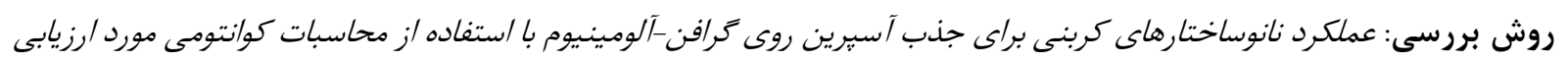

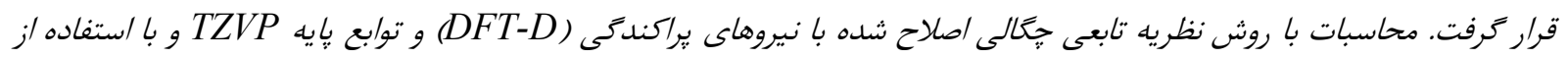

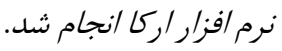

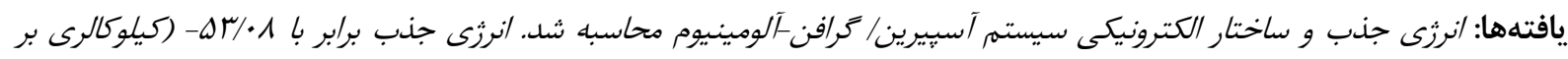

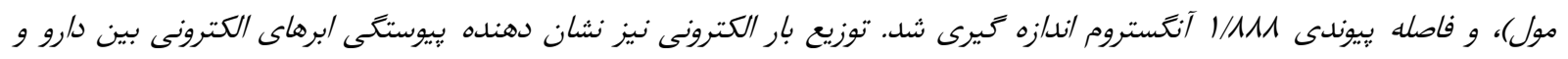

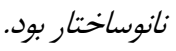

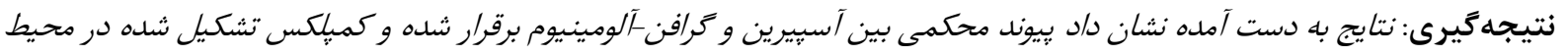

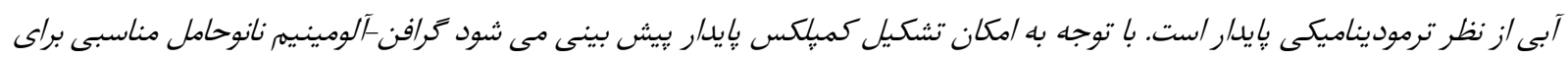

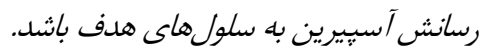

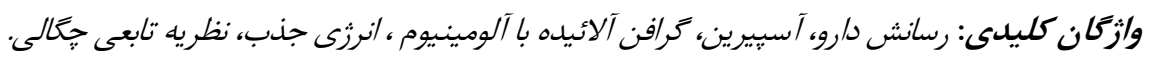

ترميم و بازسازى بافت هاى زيستى آسيب ديده در سطوح ملكولى

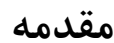

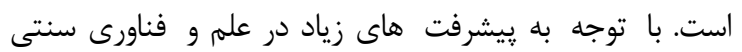

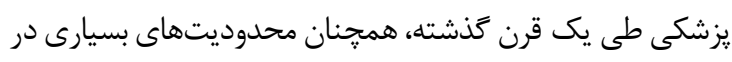

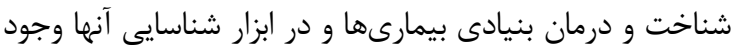

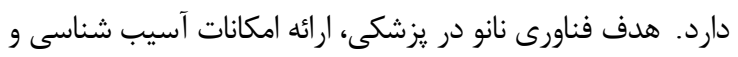

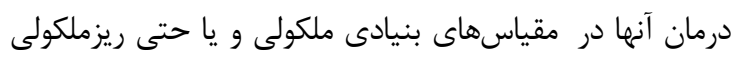

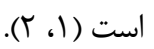

أدرس نويسنده مسئول: ايران، قائمشهر، دانشكاه آزاد اسلامى، مسعود درويش گنجى (email: Ganji_md@yahoo.com) نانوفناورى (Nano Technology) در حيطه داروسازى داراى كاربردهاى اساسى است و هدف اصلى آن، طراحى داروهاى دارئ داري نانوفناورى يزشكى (Nanomedicine) علم نظريهها، رويكردها،

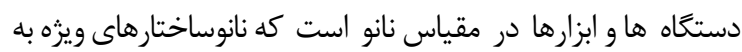
منظور شناخت، بِيشكيرى و درمان بيمارىها از طريق شناسايى،

ORCID ID: 0000-0001-8003-9682 تاريخ دريافت مقاله: QM/T/IV تاريخ خذيرش مقاله: 


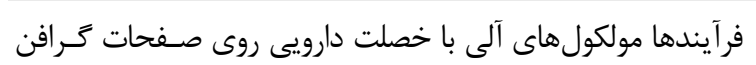
قرار مى قيرند.

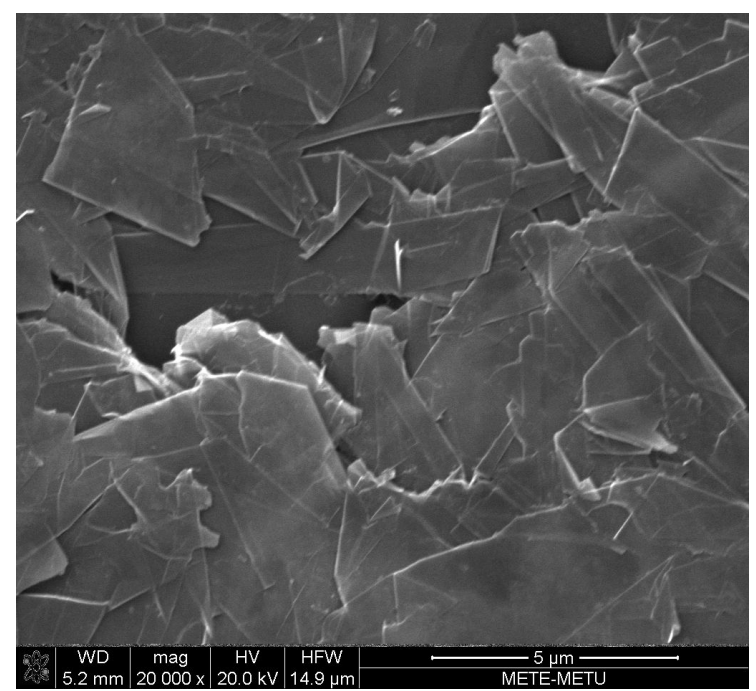

شكل ا. ساختار لايهاي كرافن با ميكروسكوٍ الكترونى روبشى

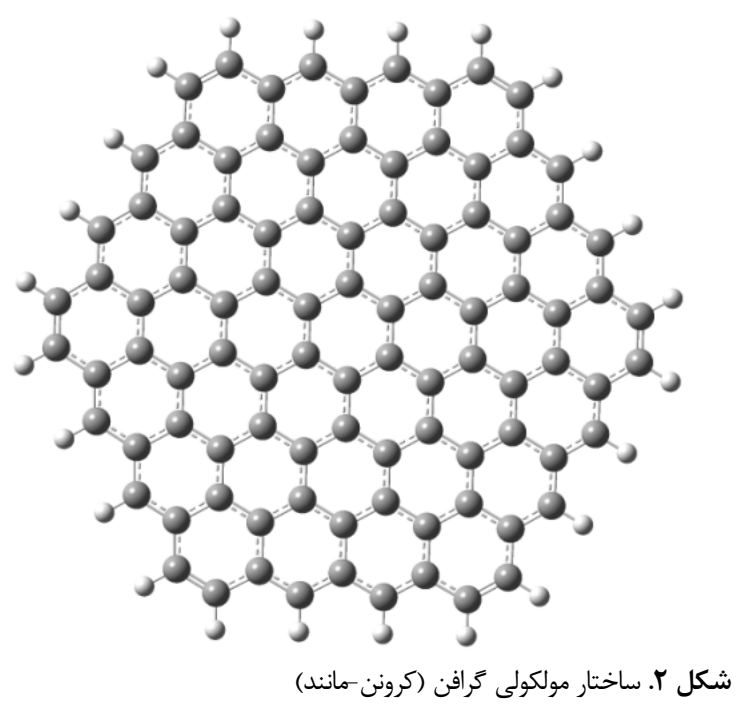

ساختار كرافن، صفحهاى شامل و9 اتم كـربن كـه انتهـاى صـفحه

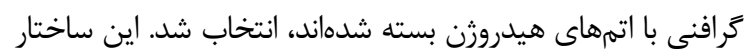

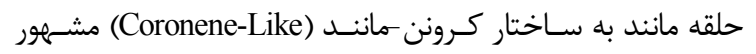

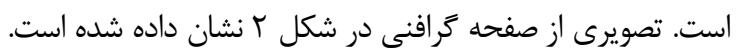

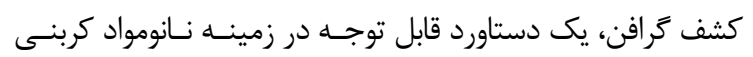

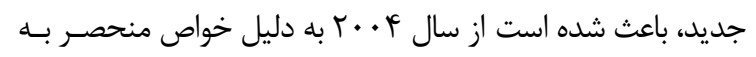

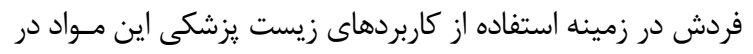

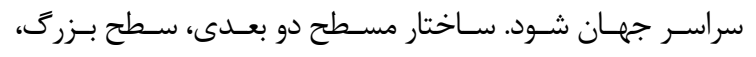

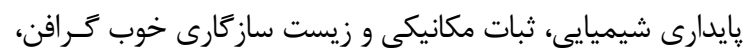

هوشمند و هدف گير بر بايه بيمار محور و بيمارى محور است. اين

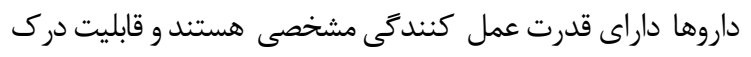

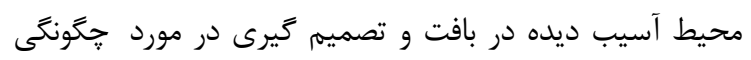

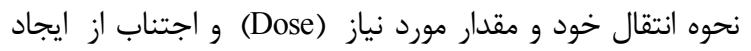
حساسيت و اثركذارى جانبى هستند. اين نوع داروها قبل از رها

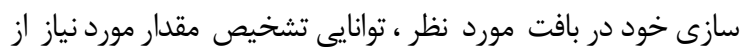

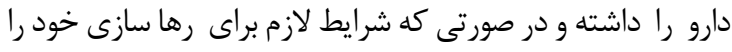

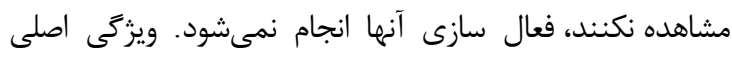

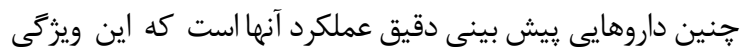

بسيار مهم در داروهاى غيرهوشمند فعلى وجود ندارد (با، ()).

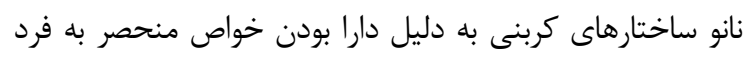

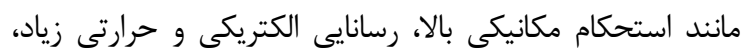

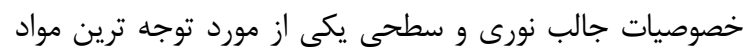

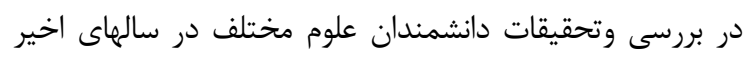

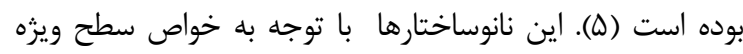

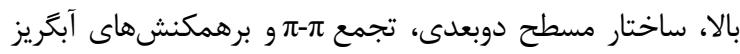

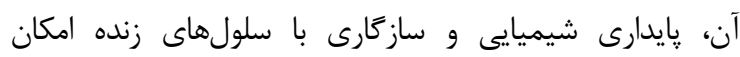

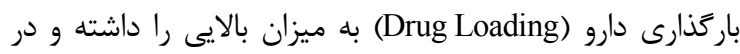

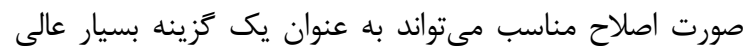
براى رهايش داروها مورد استفاده قرار كَيرد.

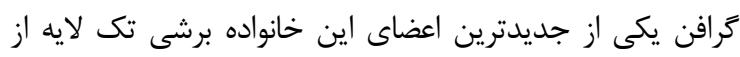

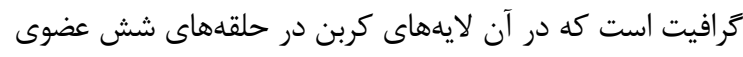

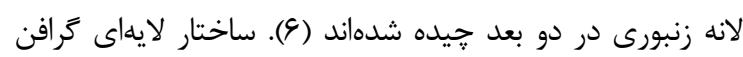

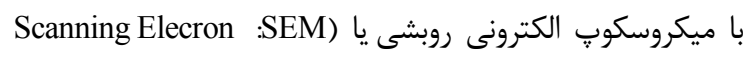
(Microscope بودن ساختار مورد نظر دارد.

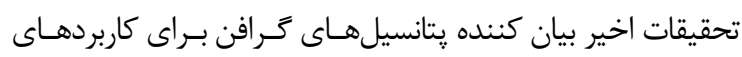

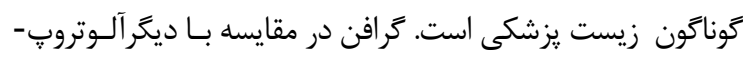

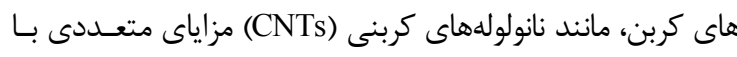

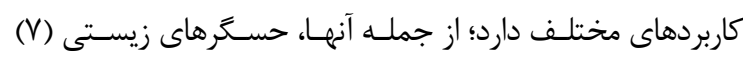

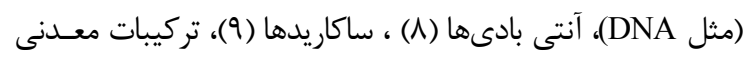

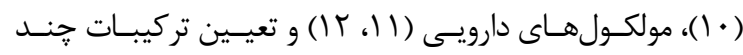

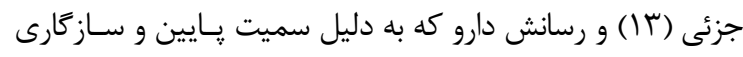

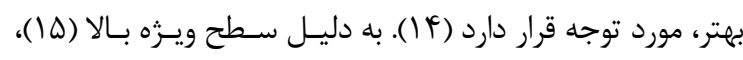

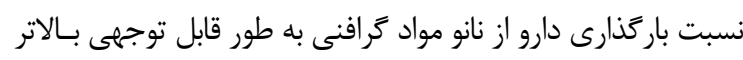

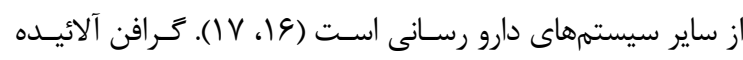

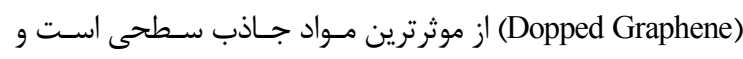

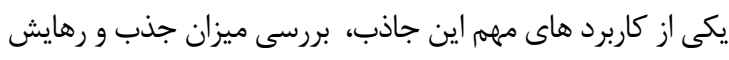

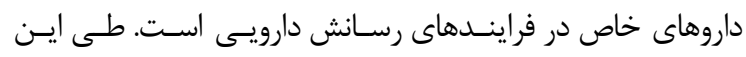


يكى از كاربردهاى جالب كرافن و اكسيد گررافن استفاده از آنها

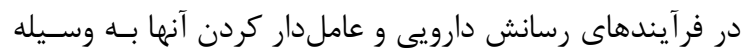

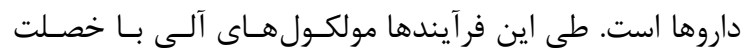

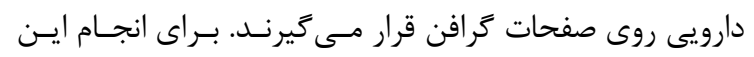

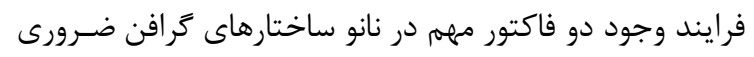

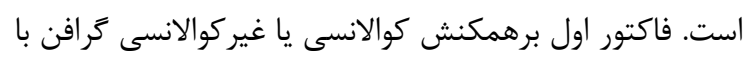

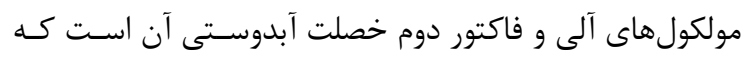

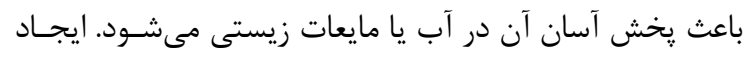

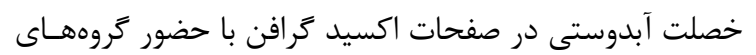

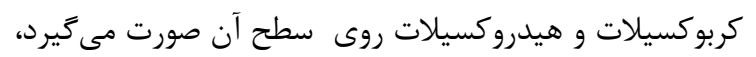

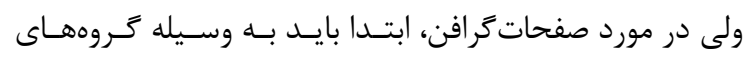

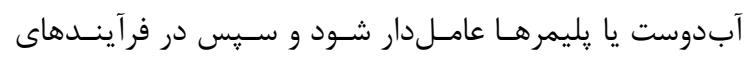

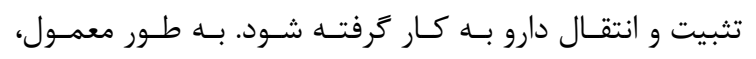

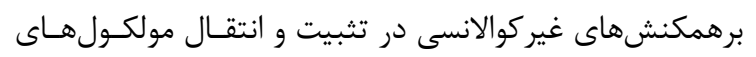

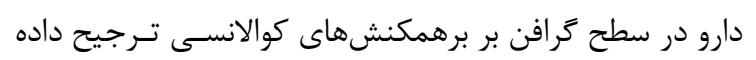

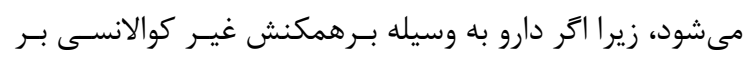

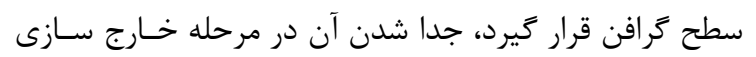

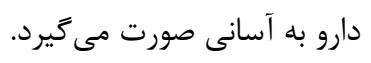

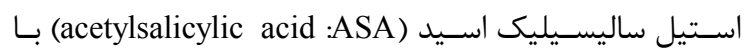

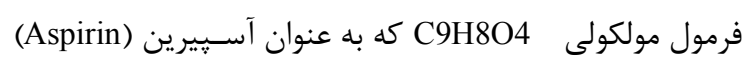

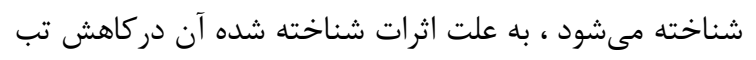

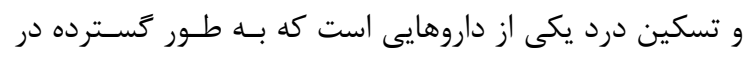

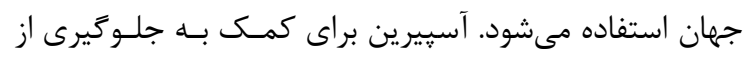

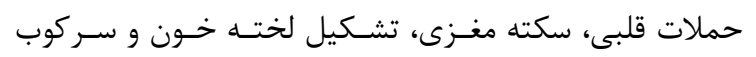

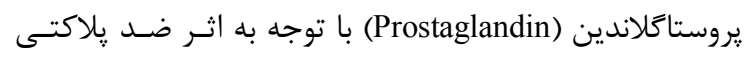

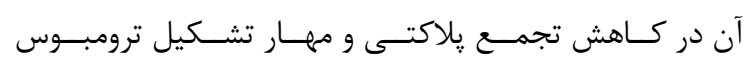
(Thrombus)

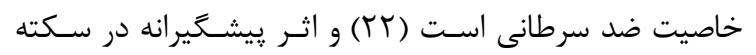

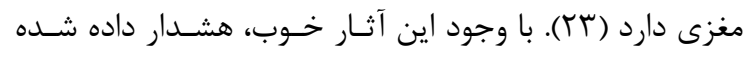

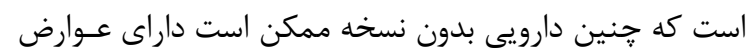

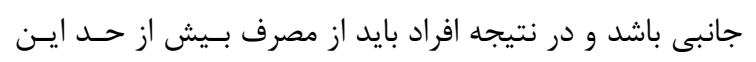

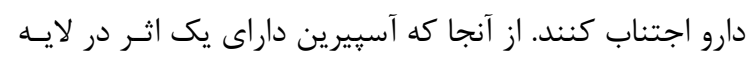

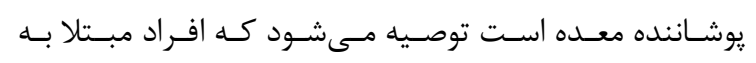

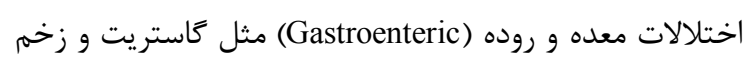

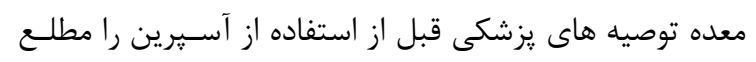

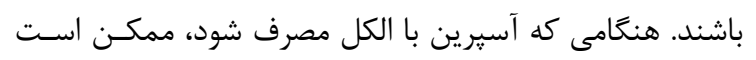

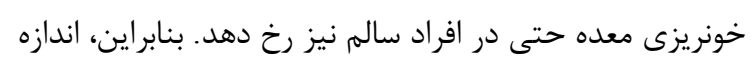
كيرى مقدار مولكول ASA در محلول و يا در بدن انسان بسيار

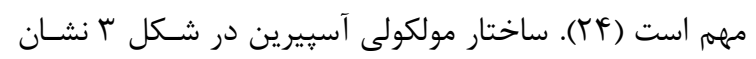

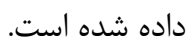

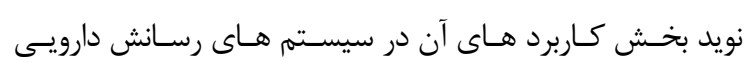
(Drug Delivery Systems :DDSs) كربن يكى از فراوان ترين عناصر در طبيعت است. اتسمهـاى كـربن

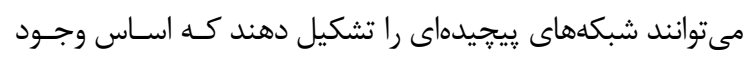

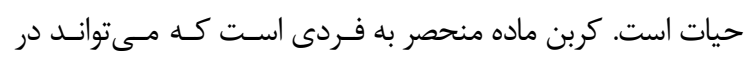

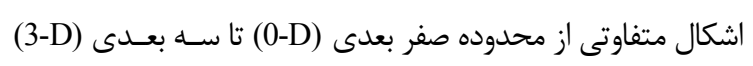
وجود داشته باشد.

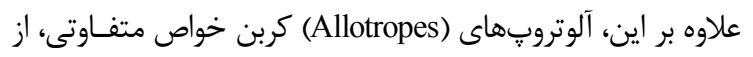

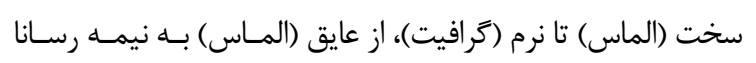

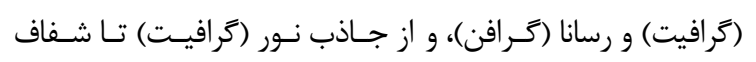

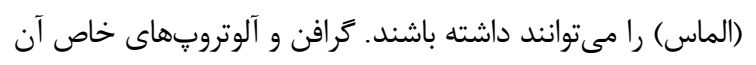

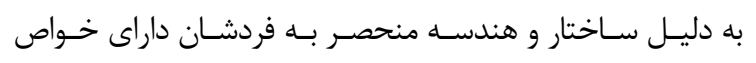

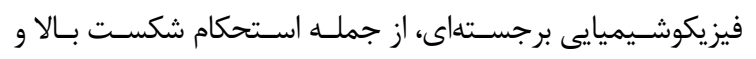

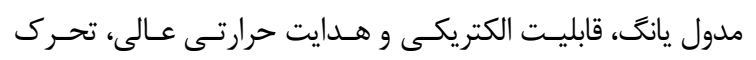

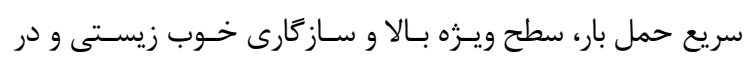

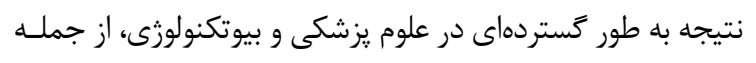

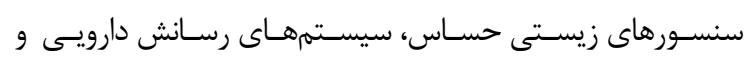

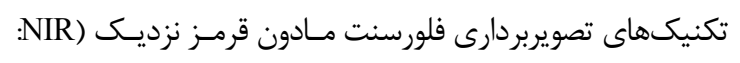
(Near Infrared

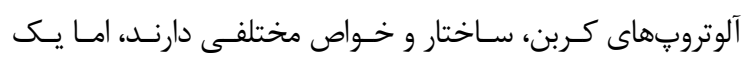

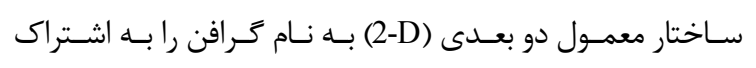

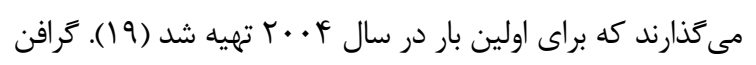

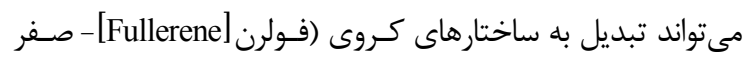

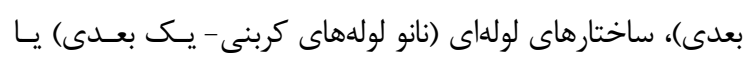

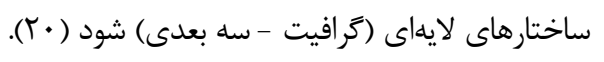

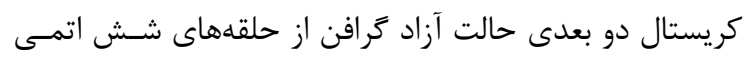

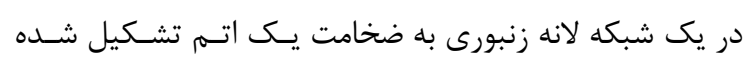

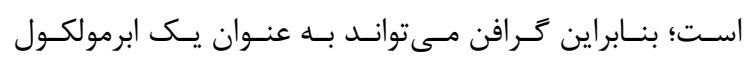

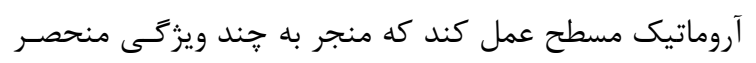
به فرد مىشود. در ساختار كرافن هر اتم كربن به سه اتم كـربن ديخـر متصـل

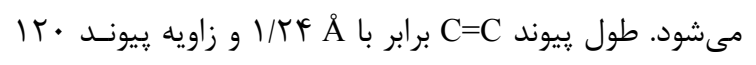

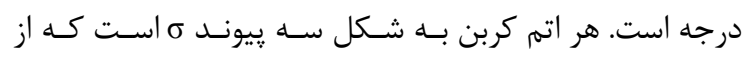

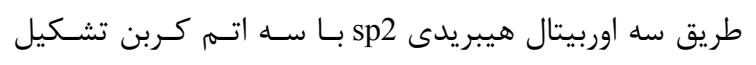

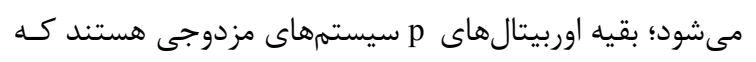

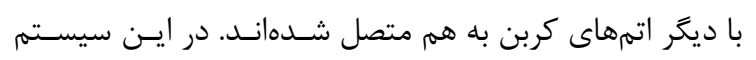

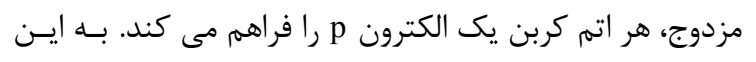

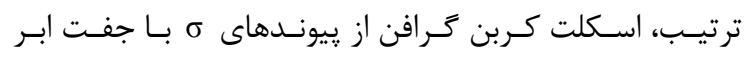
الكترونى بالا و اسكلت يايين ساخته شده است. 


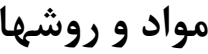

شيمى محاسباتى شاخهاي از دانش شـيمى اسـت كـهـ از مفـاهيم

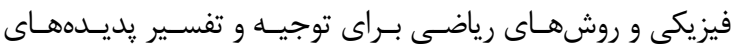

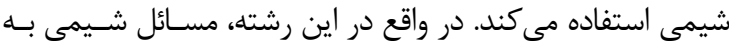

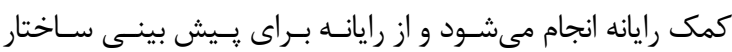
مولكولى، خواص مولكولى و واكنشهاى شـيميايى اسـتفاده مسى

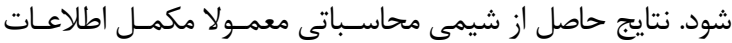

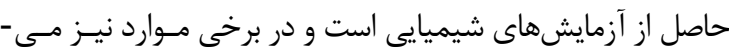
تواند به بيش بينى يديدههاى مشاهده نشده شيميايى منجر شـودي.

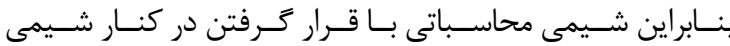

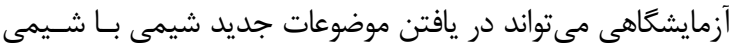
تجربى رقابت كند. شيمى محاسباتى شامل مدل سازى مولكولى، طراحسى مولكـول و

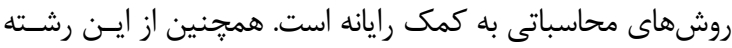

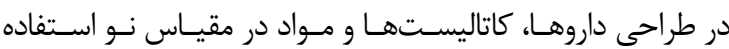

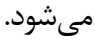

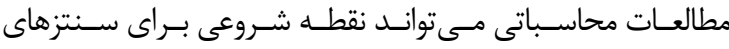

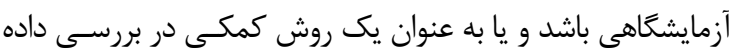
هاى تجربى مثل موقعيت نوارهاى طيف سنجى مورد استفاده قرار كيرد. با استفاده از روشهاى محاسباتى، امكان وجود مولكولهـاى آناى

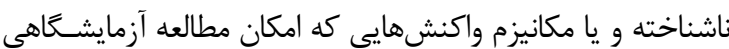

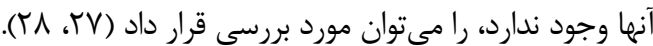

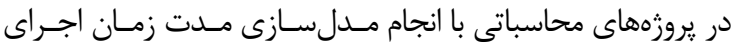

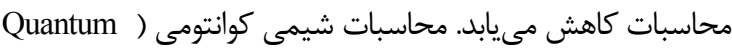
(Chemical Calcalations واكنشهـاى شـيميايى اسـت. در كنـار ديخـــ اطلاعـات، سـاختار هندسى مولكـولى (Molecular Geometry) و انـرزى صـورتبندى هاى (Conformations) مختلف، به درك بهتر واكنشهـاى فصـل

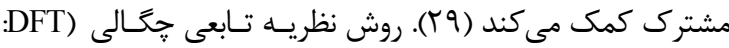
(Density Functional Theory

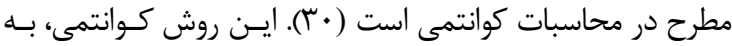

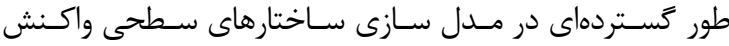

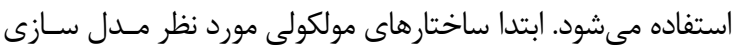

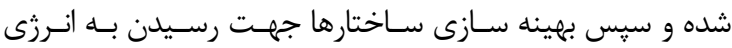

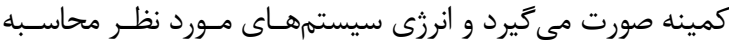

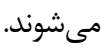
محاسبات نظريه تابعى خحالى در اين طرح، با بهـره گيــــ از نـرم

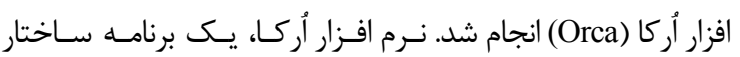

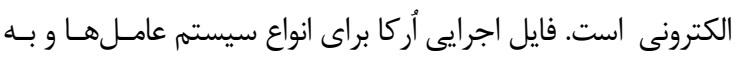

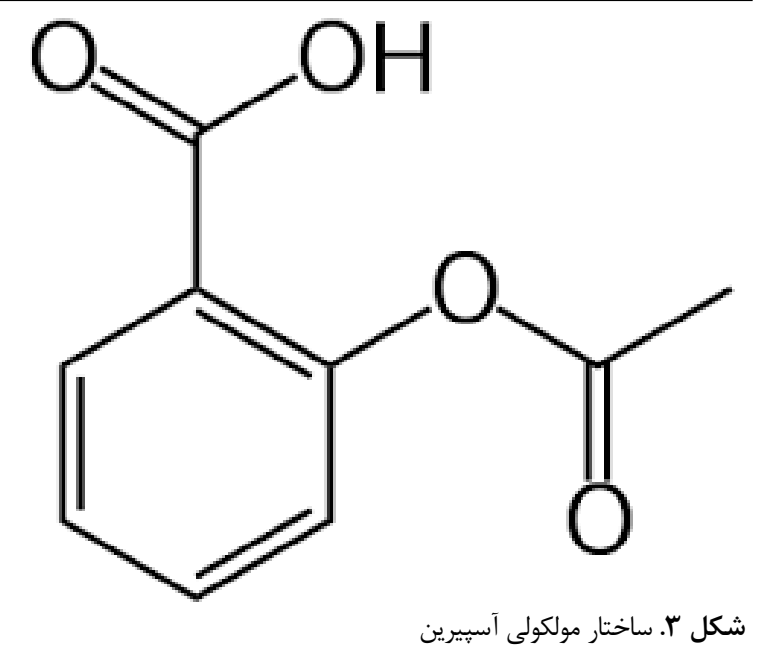

در ساختار كرافن، هر اتم كربن با سه اتم كربن ديكر بييونـد داردو و

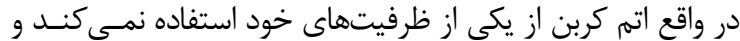

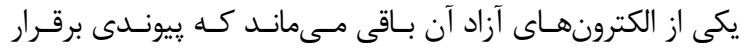

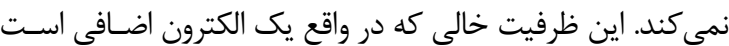

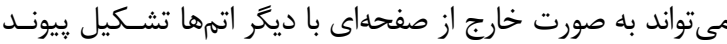

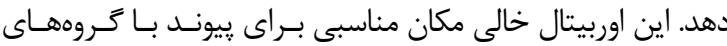
عاملى و همجنين اكسيرن است. داروى آسيرين با فرمول مولكولى C9H8O4 و با داشتن اتسمهـاى اكسيرن و هيدروزن و همجِنين حلقه آروماتيك در سـاختار خـود تمايل به برقرارى برهمكنش قوى با صفحه كـرافن را دارد. جهـت واكنش يذيرى بيشتر صفحه كَرافن، اين ساختار با فلـز آلومينيـوم

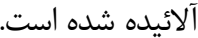
اين دارو در حضور رطوبت و يا آب به اسيد ساليسيليك و اسيد

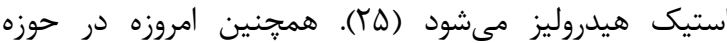

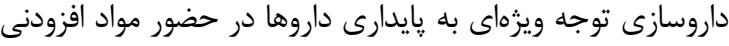

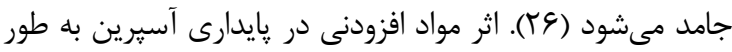

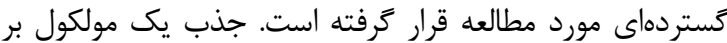
روى يك سطح مرحله اول از هر واكنش است كه توسط سطح

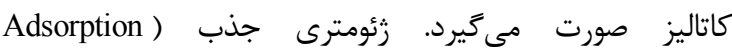
(Goemetry به منظور درك جزئيات خنين واكنشى بسيار مهرم

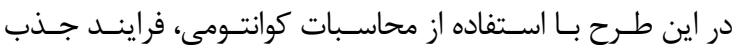
آسيرين توسط نانوساختارهاى گر افنى كه شامل كرافن آلائيـده بـا

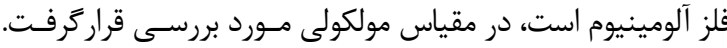

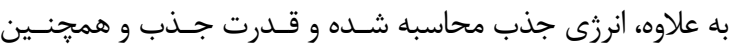
ظرفيت جذب آسبيرين توسط نانوساختارهاى مـورد نظـر بررسى إسى 


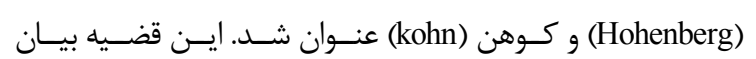

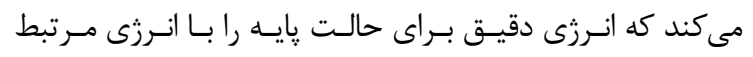

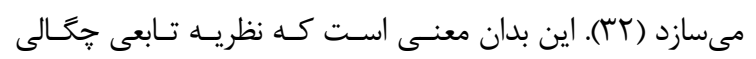

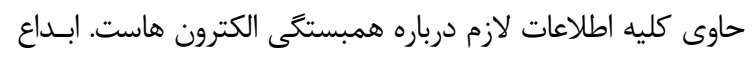

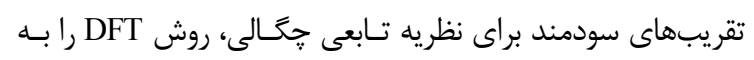
روشى ير قدرت و ير طرفدار تبديل كرده است.

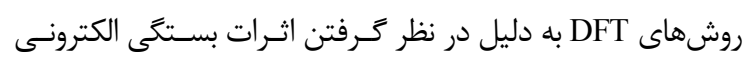

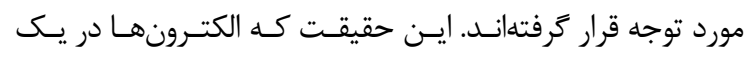

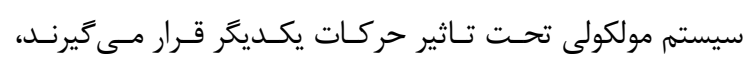
محاسبات هارترى فاك اين اثر را فقط در يكى مقـدار ميـانگين در

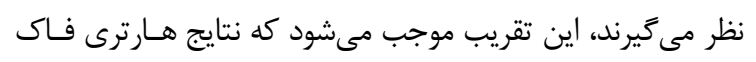
از صحت كمترى برخوردار باشند.

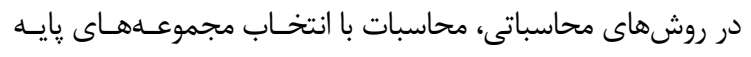

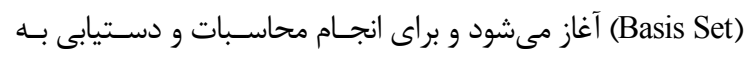

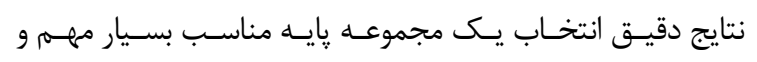

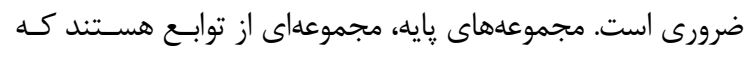
براى توصيف شكل اوربيتالها در اتمها به كار مسىرونـد و معمـولا

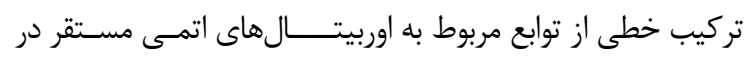

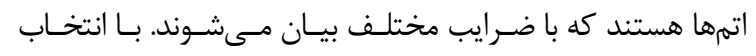

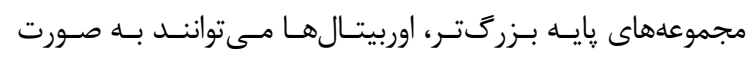

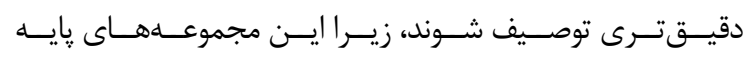

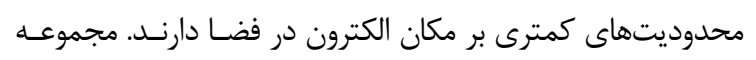

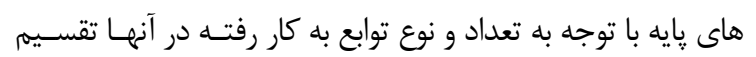
بندى مىشوند.

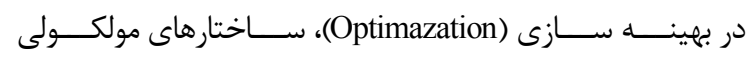

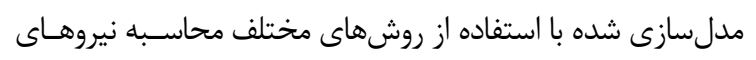

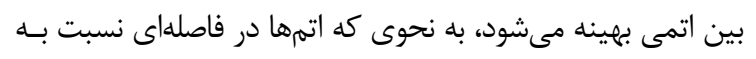

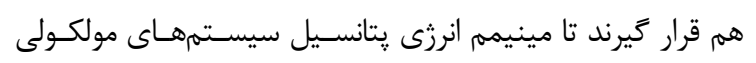

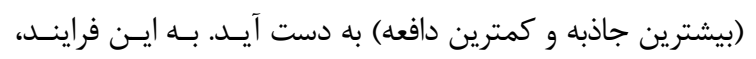
بهينه سازى ساختار مولكولى گويند.

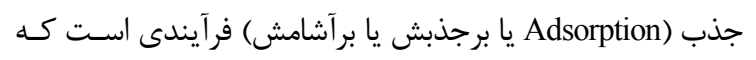

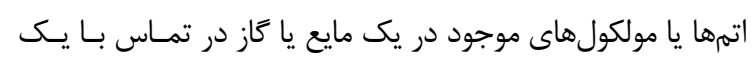

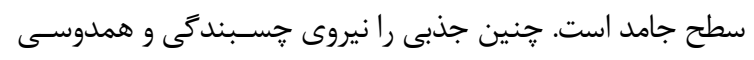

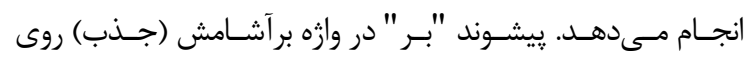

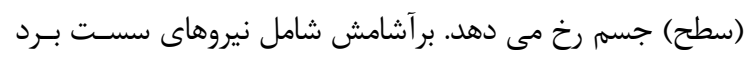

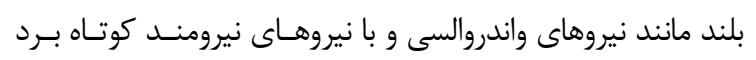
مانند كوالانسى، يونى و فلزى است. LUMO و (Highest Occupied Molecular Orbital) HOMO بــ ترتيـب كلمـات (Lowest Unoccupied Molecular Orbital) اختصارى براى بالاترين اوربيتال مولكولى اشغال شده و پايينترين
صورت رايخان در دسترس كاربران دانشخاهى است. اين نـرم افـزار،

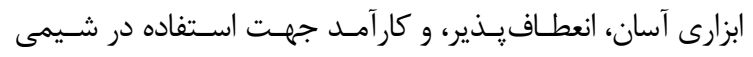

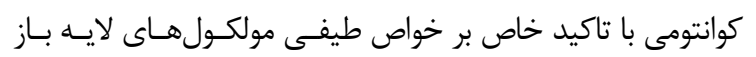

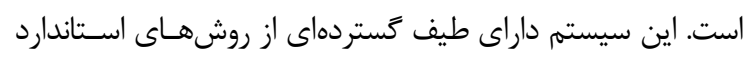

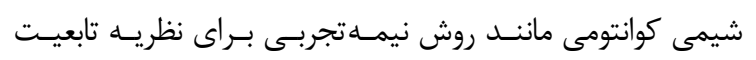

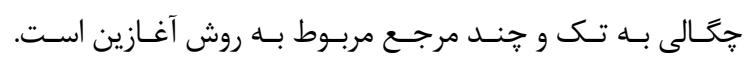

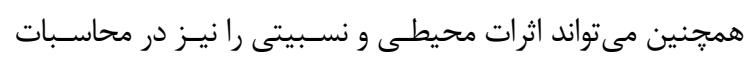

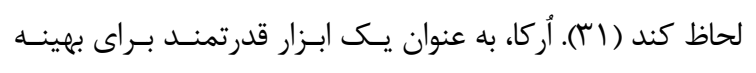

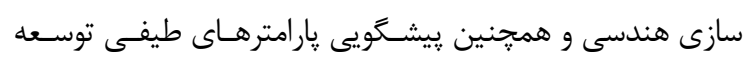

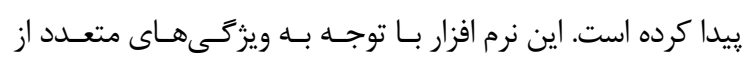

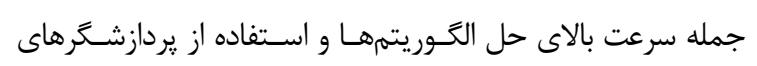

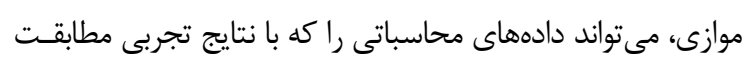

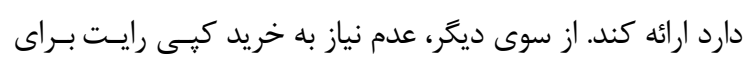

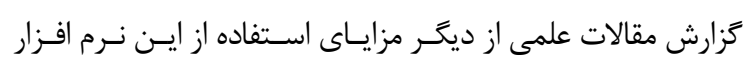
است.

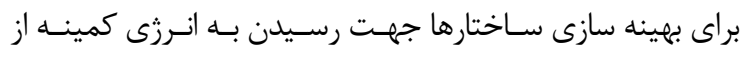

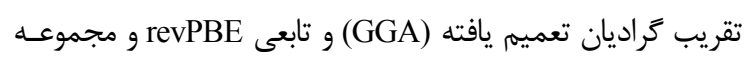

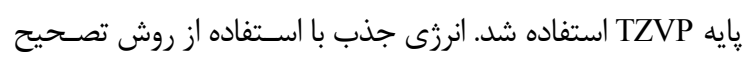

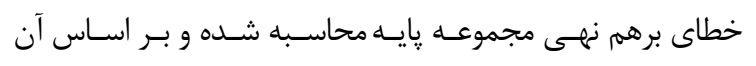

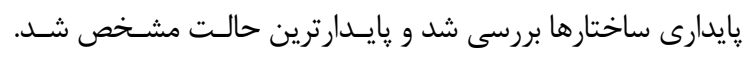

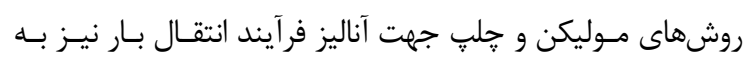

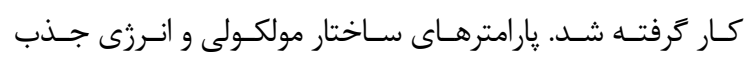
كميلكسهاى مربوطه در محيط آبـى مـورد بررسـى قـرار كرفـت.

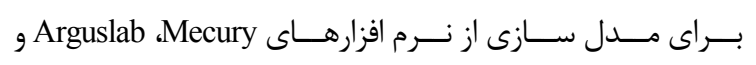
براى طراحى نانو ساختار كرافن آلائيده با آلومينيـوم

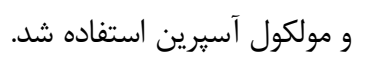

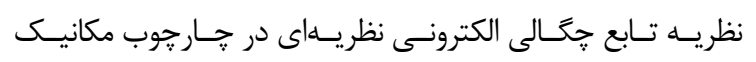

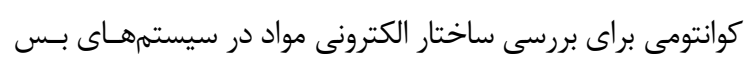

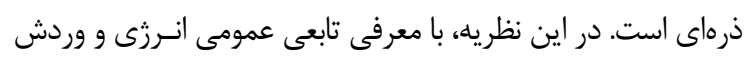

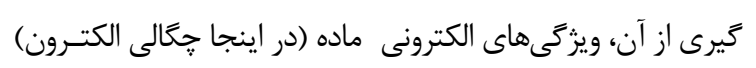

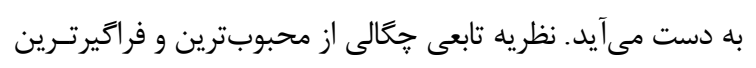

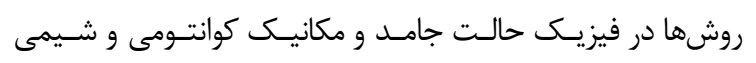

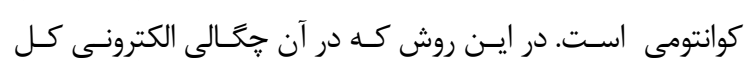
مولكول مد نظر است، محاسبه خواص مولكولى مبتنـى بــر نظريـــ

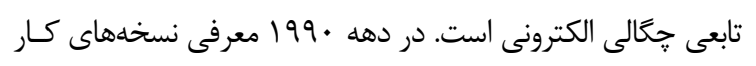

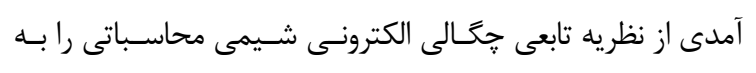

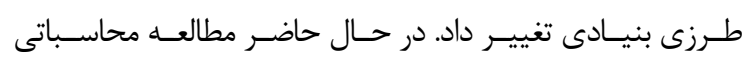
سيستمهاى آلى و تركيبات آلى رسانا با اندازه متوسـط درئ در اختيـار

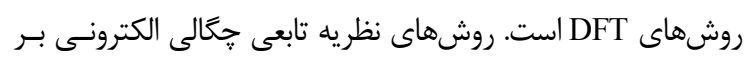

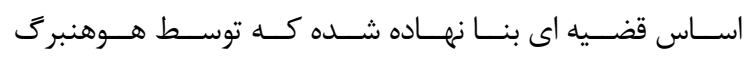



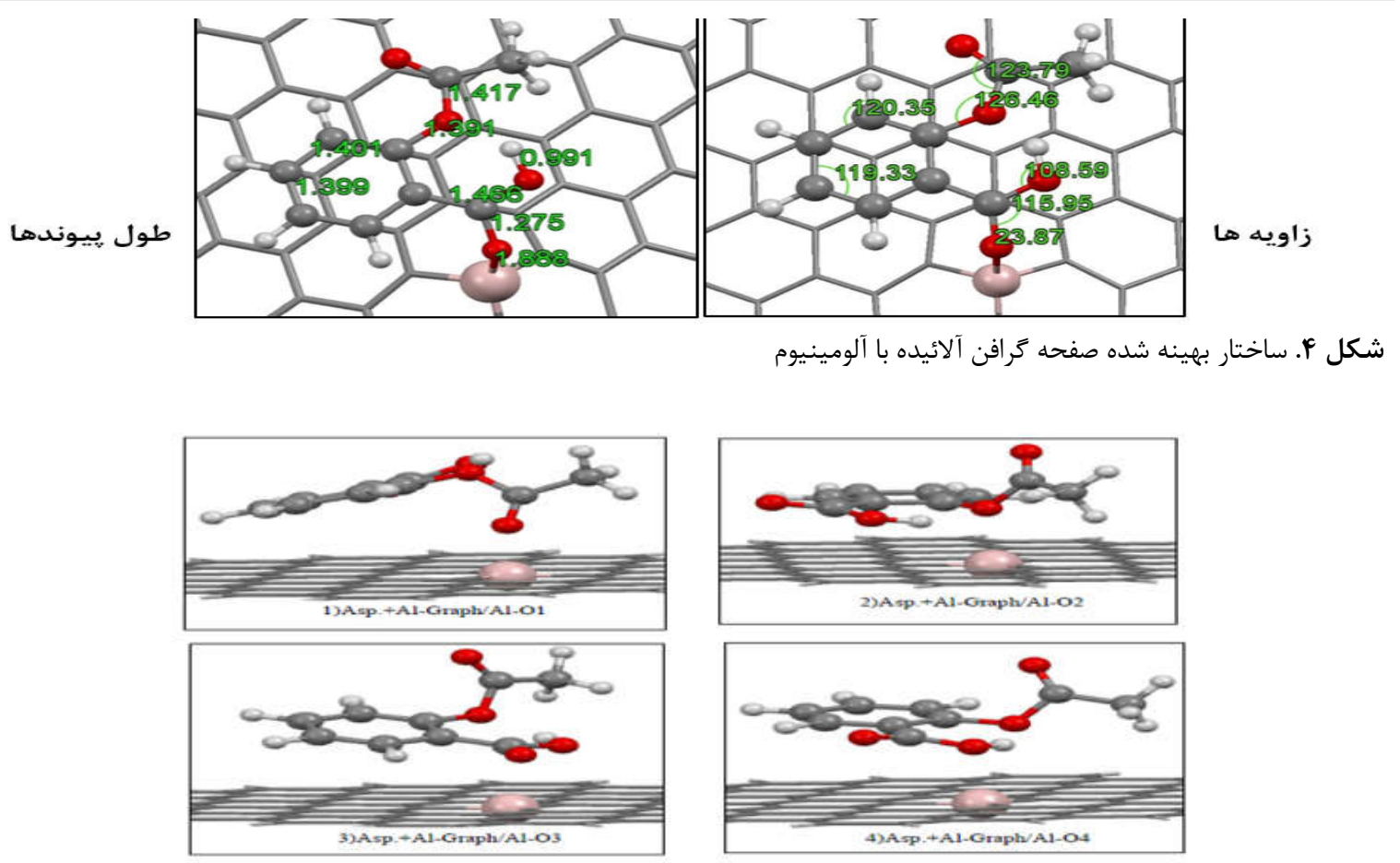

شكل ه. بِيكربندى هاى اوليه قرارگيرى آسييرين بر روى صفحه گرافن - آلومينيوم

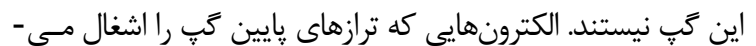

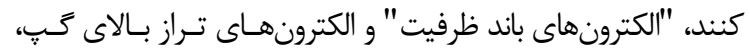

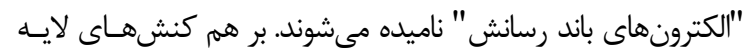

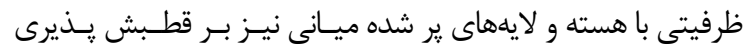

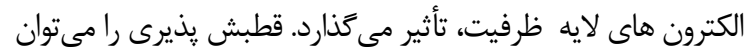

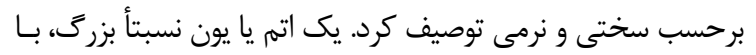

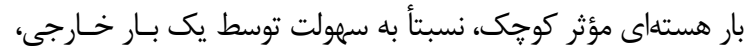
دجار انحراف (قطبش) مىشود و نرم ناميده مىشود.

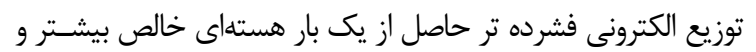

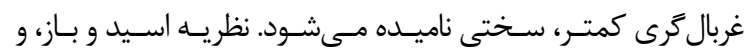

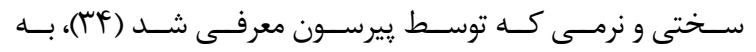
طوركسترداى در روند هاى تغييرات واكنش يذيرى كيفـى بــهـ كـار

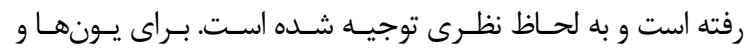

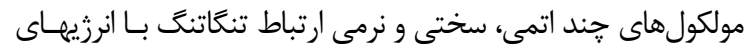

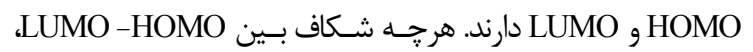
بيشتر باشد سختى بيشتر است. به لحاظ عددى، سختى تقريبأ برابـر

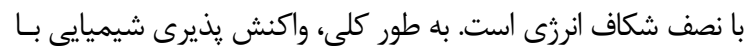

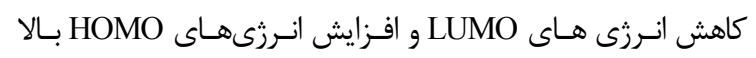
مىرود. اين بدان معناست كه گونههاى شيميايى نرمتـر، يعنسى آنهـا

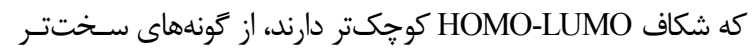

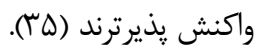

اوربيتال مولكولى اشغال نشده هستند. اختلاف انرزى بـين HOMO و LUMO شكاف بين HOMO-LUMO ناميـده مسىشـود. گَاهى اوقات HOMO-LUMO را اوربيتال مرزى مى گَويند (سا). بـه طـور تقريبى، سطح HOMO مربوط به نيمه هادىهاى آلى است كه بانـد

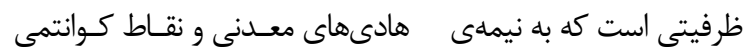

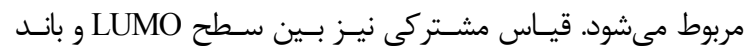
هدايت وجود دارد. در حيطه بيونــد ظرفيتـى، سـاختار از طريـق اثرات اسـتخلافىى يــا

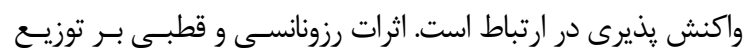

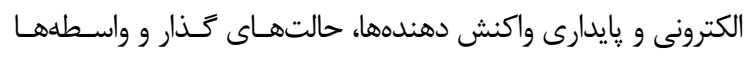

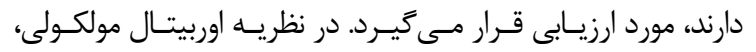

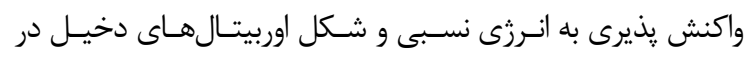

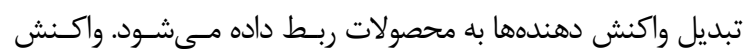

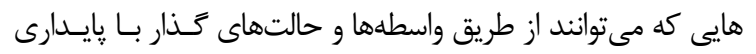
كمتر رخ دهند، مطلوبتر بوده و سريعتر بيش مى مىروند.

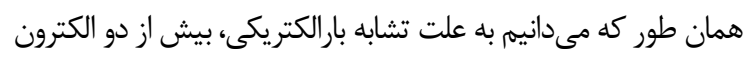

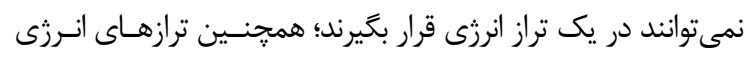
بسيار نزديك به هم هستند، آنقدر نزديك كه بـهـ صـورت يـك بـ بـازه

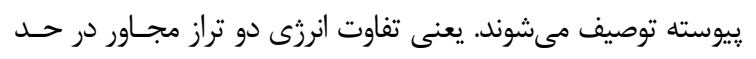

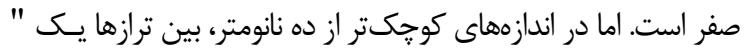

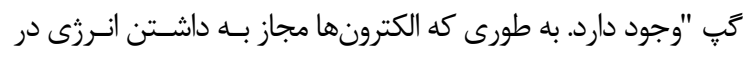




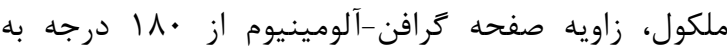

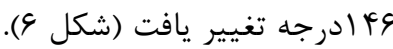

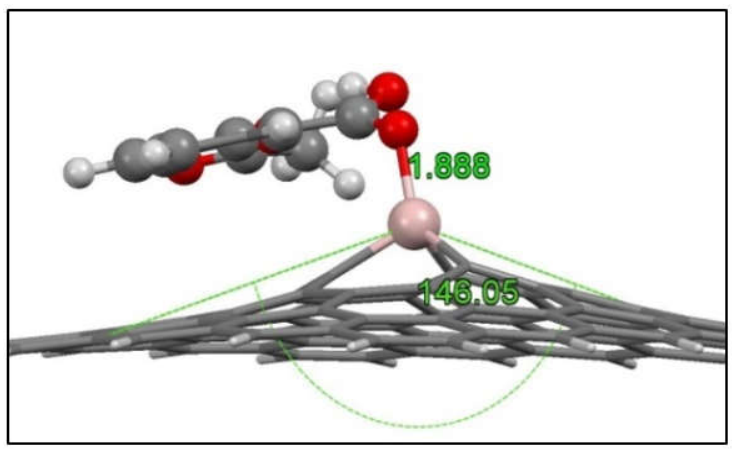

شكل 9. ساختار تعادلى نهايى آسييرين روى صفحه گرافنآلومينيوم (نماى جانبى)

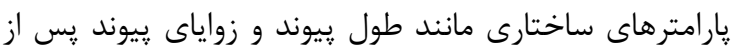
جذب در ملكول آسييرين در شكل V نشان داده شده است.

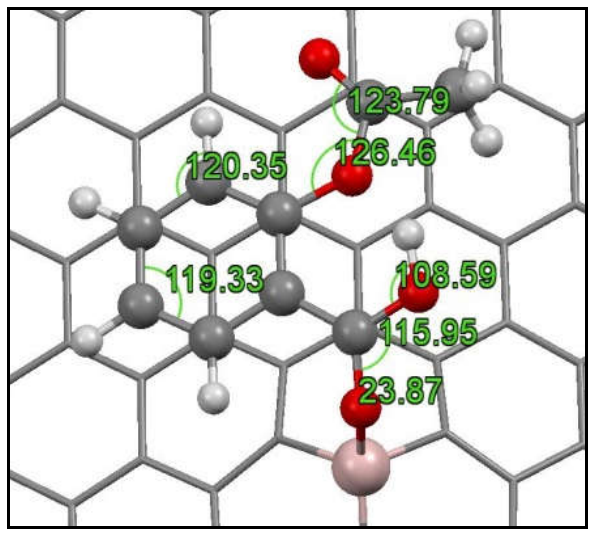

زاويلها

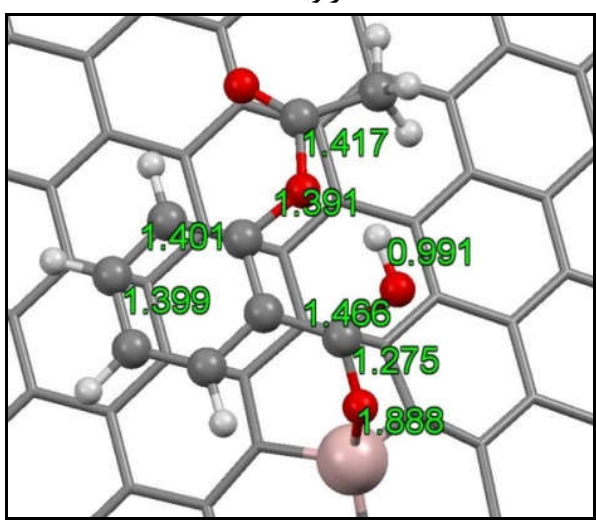

طول زيوندها

شكل V- زوايا و طول ييوندهاى آسييرين روى صفحه گرافن - آلومينيوم يس از جذب (نماى بالا)
برهمكنش داروى آسيبير ين با گر افن -آلومينيوم در اين يروهش برهمكنش بين داروى آسييرين با صفحه كرافن-آلومينيوم مورد بررسى قرار گرفت. از آنجايى كه

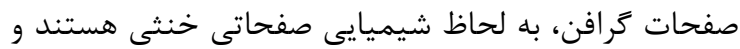
واكنش يذيرى اندكى در برابر ملكولهاى مختلف دارند، قرار دادن يك فلز نظير آلومينيوم بر روى اين صفحه، واكنش يذيرى شيميايى و خواص گرافن را به شدت تحت تاثير قرار خواهد داد. از اين روى در اين قسمت، ابتدا يك اتم كربن از صفحه گرافن، با يك اتم آلومينيوم جايگزين شده و ساختار جديد، بهينه سازى شد. ساختار بهينه شده در شكل ع أشان داده شده است. به منظور يافتن مناسبترين حالت جاى جيرى ملكول

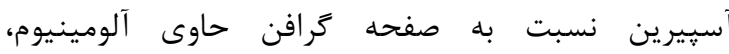
ييكربندىهاى اوليه مختلفى به عنوان حالتهاى اوليه مدلسازى شده و تحت بهينه سازى ساختارى كامل قرار

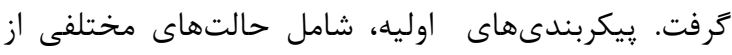
جاى گيرى ملكول آسييرين بر روى اتم آلومينيوم موجود در

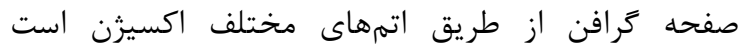

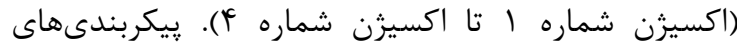
اوليه در شكل ه نشان داده شده است.

جدول ا. انرزى جذب و فاصله تعادلى در برهمكنش آسييرين با

\begin{tabular}{|c|c|c|}
\hline نوع يیكربندى & انرزى جذب (eV) & فاصله تعادلى(A) \\
\hline Al-O1 & $-1 / 91 \wedge$ & $1 / 19$. \\
\hline $\mathrm{Al}-\mathrm{O} 2$ & $-1 / \Delta S T$ & $1 / 999$ \\
\hline Al-O3 & $-r / r \cdot r$ & $1 / \wedge \wedge \Lambda$ \\
\hline $\mathrm{Al}-\mathrm{O} 4$ & $-1 / V V F$ & $1 / 991$ \\
\hline
\end{tabular}

״س از بهينه سازى ساختارى كامل و انجام محاسبات مربوط به انرزى جذب كه نتايج آن در جدول ا درجيه سله شده است، مشخص شد كه ييكربندى شماره r منفىترين انرزى جذب را داشته و به عنوان يايدارترين حالت به لحاظ انرزى

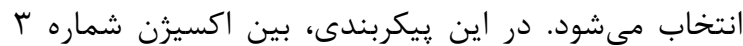
مجاور اتم كربن حاوى گروه هيدروكسيل در آسييرين با اتم آلومينيوم موجود در صفحه گرافن، جاذبه برقرار شده است. انرزى جذب حالت ذكر شده كه پايدارترين حالت است، در

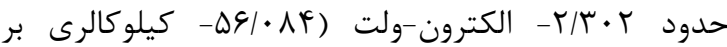
مول) محاسبه شد. فاصله تعادلى نيز برابر با 1991/1) 


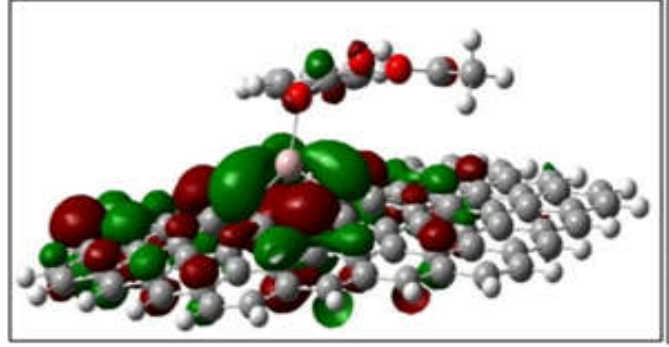

اسيتين يايين

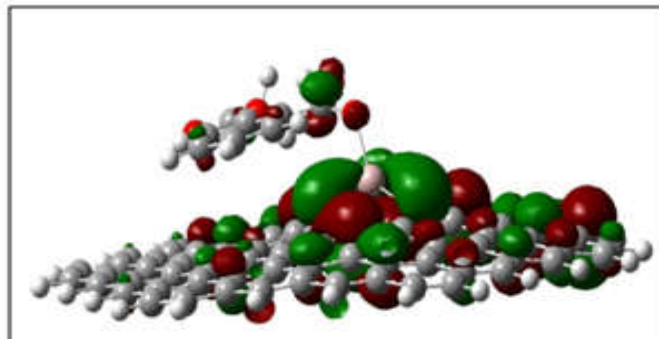

اسيين يايين

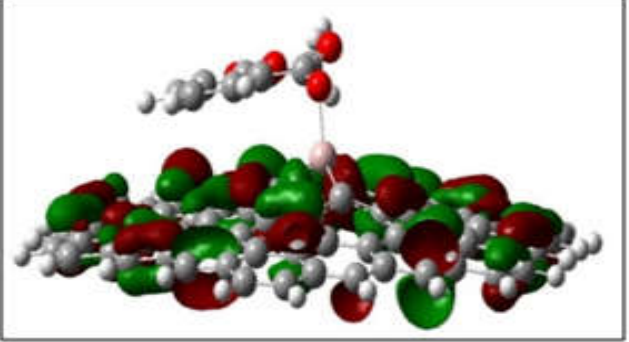

اسينين يالا

(I)

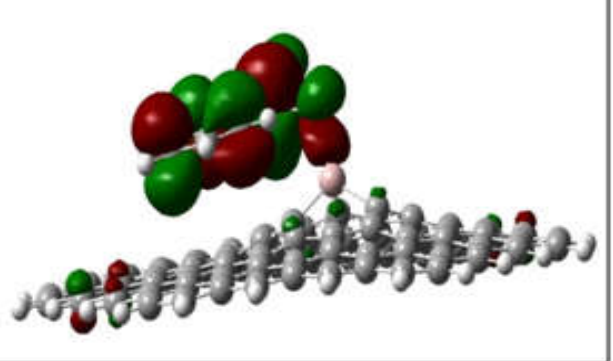

اسيين يالا

(ب)

شكل ^. تصوير اوربيتالهاى مولكولى (آ) هومو و (ب) لومو در حالتهاى اسيين بالا و پايين براى سيستم آسييرين/ گرافن-آلومينيوم

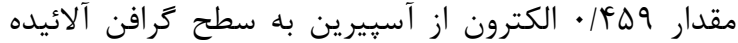
با آلومينيوم منتقل شده است. جهت اطمينان بيشتر آناليز انتقال بار جلٍ كه داراى دقت بالاترى است نيز محاسبه شد كه اين ميزان برابر با • • • • الكترون است. در ادامه سطوح انرزى اوربيتال هاى هومو و لومو در حالتهاى اسيين

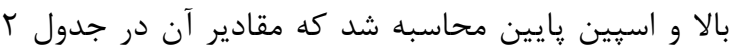

$$
\text { كزارش شده است. }
$$

تصاوير هومو لوموى به دست آمده در حالتهاى اسيين بالا و پايين

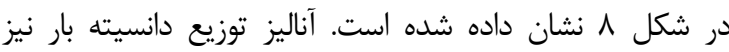
محاسبه شد و تصوير آن در شكل 9 قابل مشاهده است. در مرحله خواص مولكولى كميلكس در حالتهاى اسيين

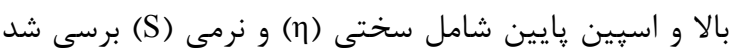
و براى مقايسه، مقادير خواص مولكولى آسييرين خالص نيز محاسبه شد كه نتايج آن در جدول س نشان داده شده است.

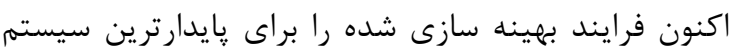

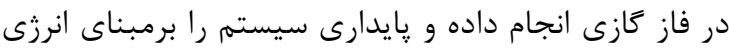

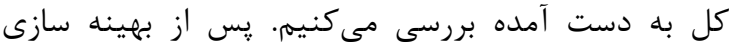

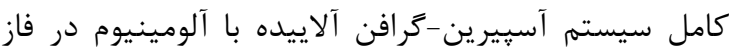
كازى و با حذف اثر حلال، تغييرات انرزى جذب برابر برابر

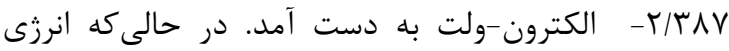
جذب سيستم با اثر حلال (ץ/ץ/ץ- الكترون-ولت) است.
ز شكل بدست آمده مشاهده مىشود ييوند C=O نزديك اتم

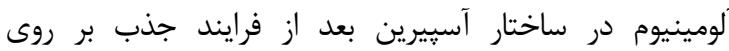

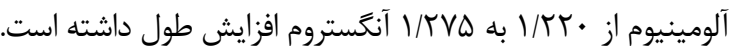
همجنين ييوند C-C متصل به گروه كربونيل در ساختار آسييرين،

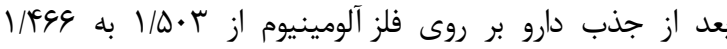
آنگستروم كاهش طول داشته است.

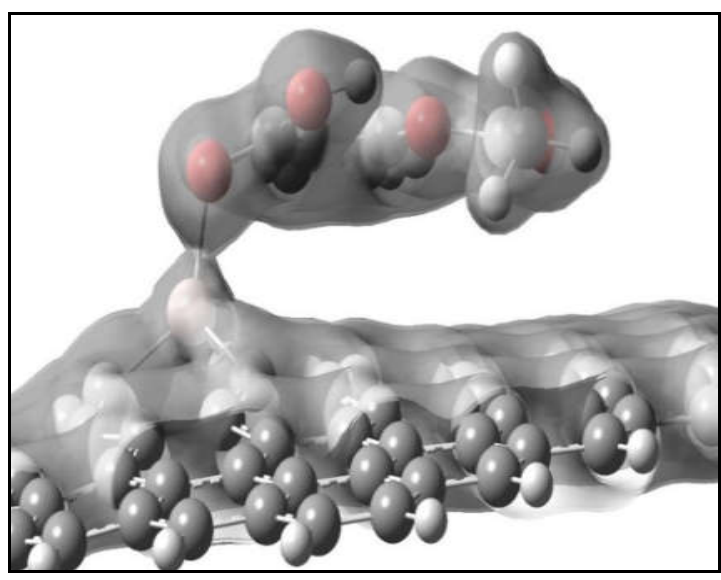

شكل 9. تصوير توزيع دانسيته بار براى سيستم آسييرين-كرافن

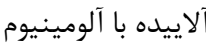

براى بررسى ميزان قدرت جذب ميان دو گونه، آناليز بار موليكن بعد از فرآيند جذب انب انجام شد و نتايج نشان داد 


\begin{tabular}{|c|c|c|c|c|}
\hline نوع يِكربندى & انرزى هومو (eV) اسيين & 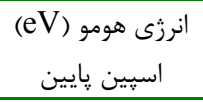 & انرزى لومو (eV) اسيّن & 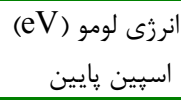 \\
\hline O1-Al & $-\psi / / M \Lambda$ & $-F / F Y F$ & $-r / / Q F$ & $-r / 999$ \\
\hline $\mathrm{O} 2-\mathrm{Al}$ & - F/THG & - F/fF. & - M/IMF & $-r / \cdot 11$ \\
\hline $\mathrm{O} 3-\mathrm{Al}$ & $-f / l v q$ & $-F / f \mid r$ & سצr/r- & $-r / 9 \Delta 9$ \\
\hline $\mathrm{O} 4-\mathrm{Al}$ & $-F / r \mid q$ & - F/FFT & - & $-r / 994$ \\
\hline
\end{tabular}

\begin{tabular}{|c|c|c|c|}
\hline 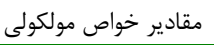 & آسبيرين & آسبيرين-كرافن آلائيده با آلومينيوم (در حالت اسِين بالا) & آسبيرين-كرافن آلاييده با آلومينيوم (در حالت اسِيين پايين) \\
\hline$\eta(\mathrm{eV})$ & $1 / 991$ & $\cdot / 4 \cdot \Lambda$ & $\cdot / 4 t \wedge$ \\
\hline $\mathrm{S}(\mathrm{eV})$ & $\cdot / T \Delta \cdot$ & I/THF & $r / 1 \Lambda \Lambda$ \\
\hline كَّ انرزى (eV) & ५/৭१९ &.$|1| 9$ & $\cdot / 4 \Delta S$ \\
\hline
\end{tabular}

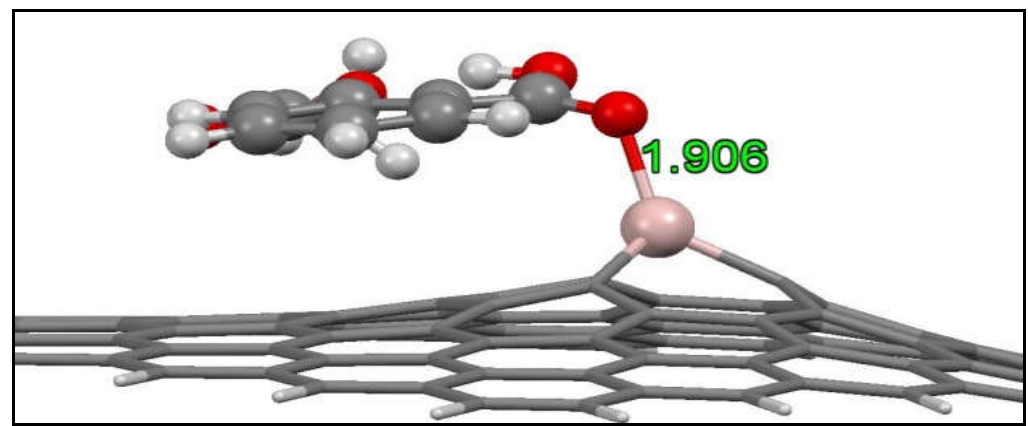

شكل •ا. ساختار تعادلى نهايى آسييرين روى كرافن آلاييده با آلومينيوم در فاز كازى

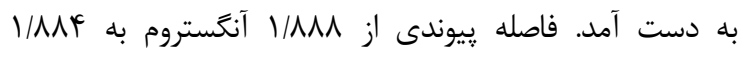
آنخستروم كاهش يافت (شكل I (1).

\section{بحث}

امروزه نانوساختارهاى كربنى به عنوان حاملهاى نانويى با

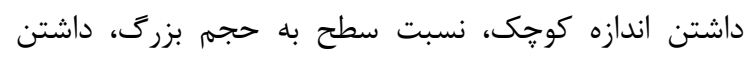

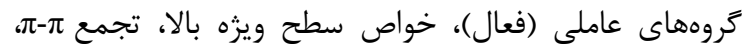
برهم كنشهاى آبخريز، ساز ₹ارى با سلولهاى زنده و همجنين برهمكنش مناسب اين تركيبات با ملكولهاى دارويى در برى سيستمهاى جديد رسانش دارويى بسيار مورد توجه هستند.

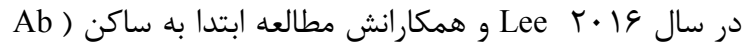
جذب آسيرين روى نانو لوله كربنى و نانو لولههاى (Initio

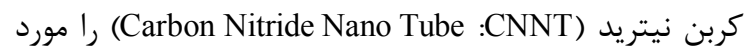
بررسى قرار دادند. در اين :يزوهش با استفاده از نظريه تابعى

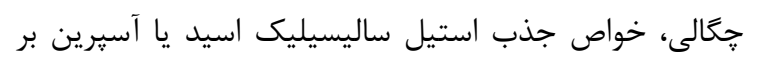

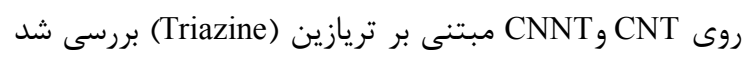

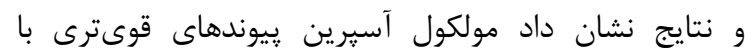

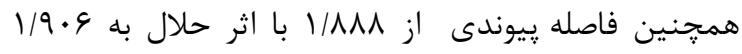
آنگستروم در فاز كَازى افزايش يافت (شكل • (1).

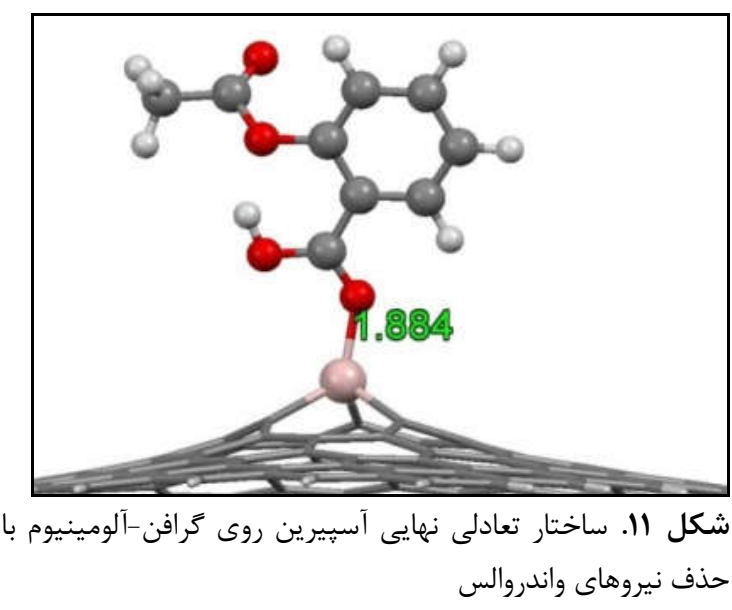

جهت بررسى اثر نيروهاى واندروالس، بهينه سازى براى

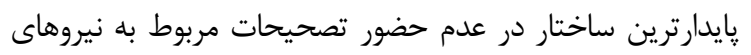

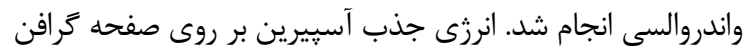

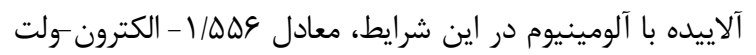


براى همه اشكال (ييكر بندى) جذب شناخته شده است. جهار

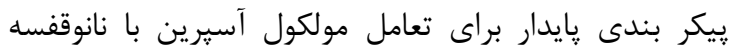

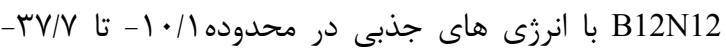

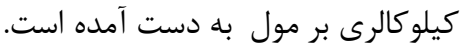

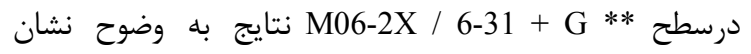

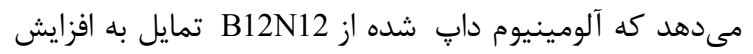

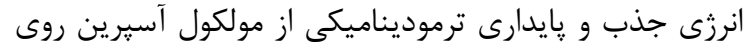

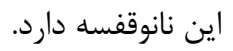

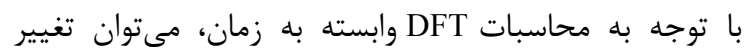

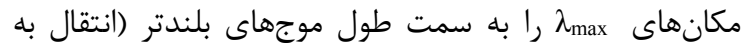

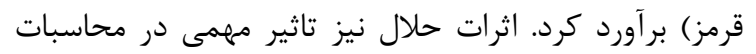
طيف جذبى الكترونيكى كميلكسهاى

در سال r T Y T توسط Datt و همكارانش مطالعه تجربى و

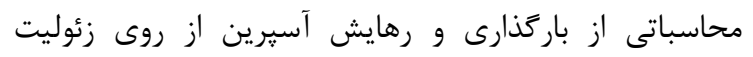

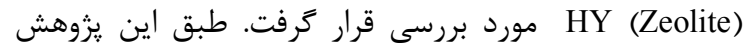

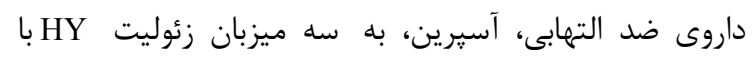
نسبتهاى ه ه • باو •ع از سيليس، به آلومينيوم باركذارى مىشود. ميزان باركذارى آسيرين در نمونه زئوليت

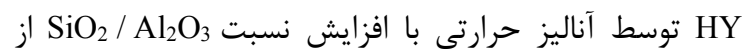

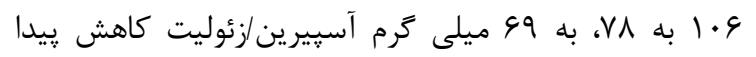
مى كند. اندازه كيرى ناحيه سطح و حجم منافذ، با استفاده از

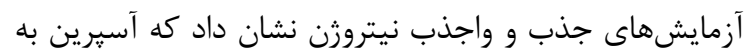

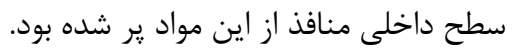

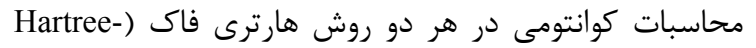

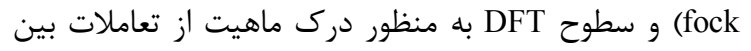

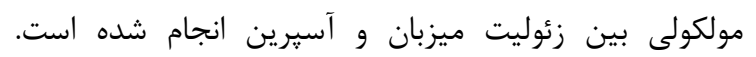
رهايش آسيرين از HY وابسته به آب كريزى زئين

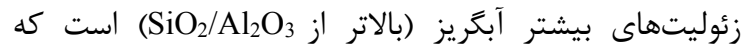

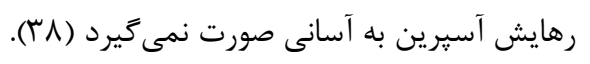

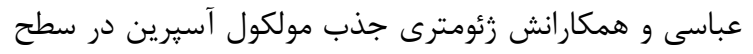

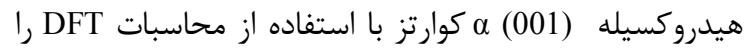
بررسى كردند. زئومترى جذب بهينه سازى شده نشان مى دهد

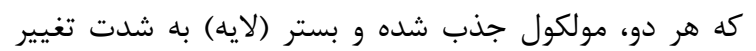

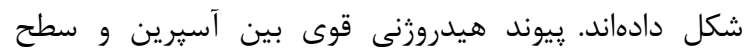

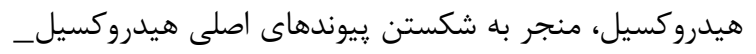

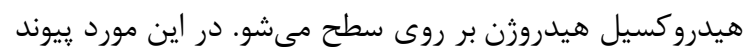

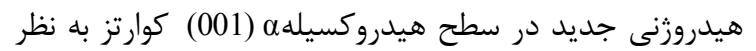

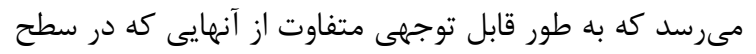

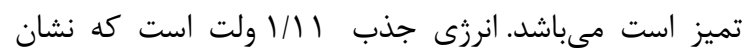

CNNT با انرزى جذبى \&V • • الكترون-ولت نسبت به CNT با

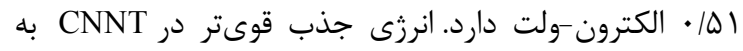
واكنش يذيرى بالاى اتمهاى نيتروزن خود با بيوند الكترونى بالا مىتوان نسبت داد. CNNT ممانهاى دوقطبى الكتريكى

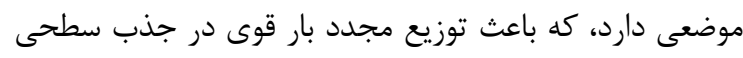

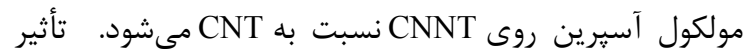
يكى ميدان الكتريكى خارجى در خواص جذبى آسيرين در اين

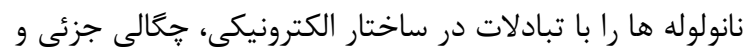

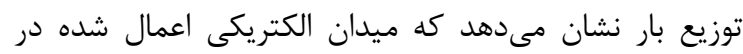
طول يك جهت خاص، مولكول آسيرين را وادار مى كند كه در

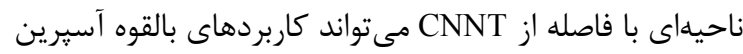
را بروز دهد (TF) در تحقيقات ديخرى كه توسط عباسى و همكارانش در سال

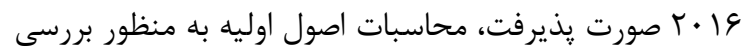
برهمكنش مولكول آسيرين با نانوذرات (Anatase)

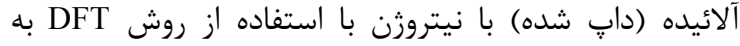

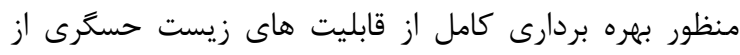

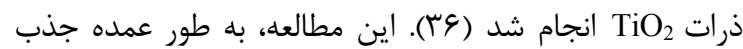
مولكول آسيرين را روى ينج برابر كوئورديناسيون سايت اتم تيتانيوم از نانوذرات

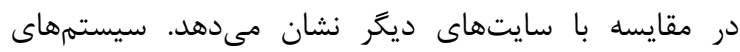
كميلكس متشكل از مولكول آسيرين كه جهت كيرى آنها به به دهائ

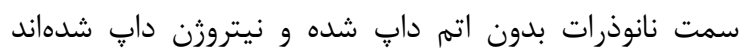

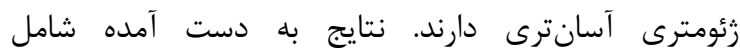
يارامترهاى ساختارى از قبيل طول باند و انرزى سيستمها

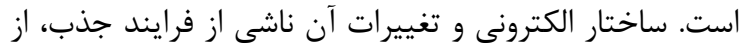

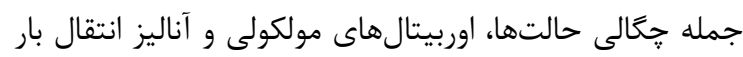
موليكن Mulliken Charge Transfer Analysis) مورد مطالعه قرار كرفته است و نشان مىدهد كه جذب مولكول

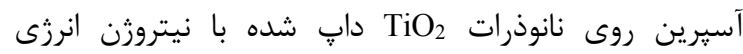

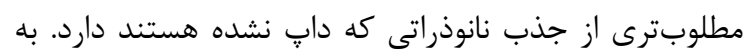
طور نظرى و با درك كلى روى برهمكنش نانوذرات

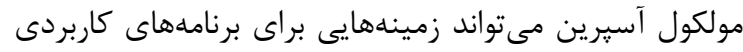

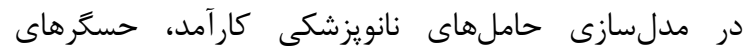

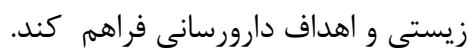

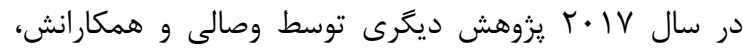

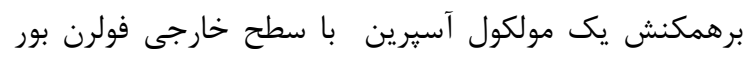
نيتريد (B12N12) مانند نانوقفسه (Nanocage) با استفاده از بران

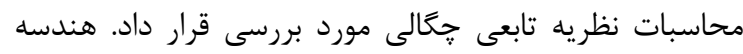

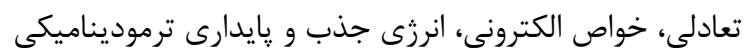




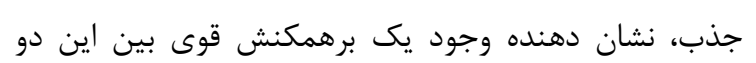

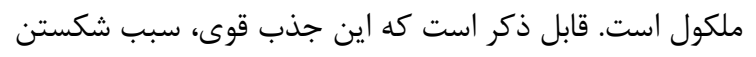

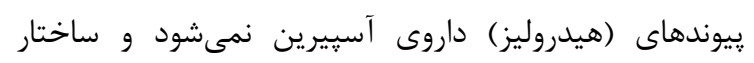
مولكولى آن را تخر يب نمى كند.

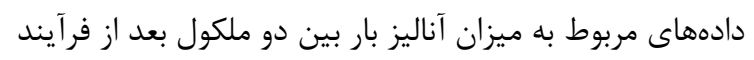

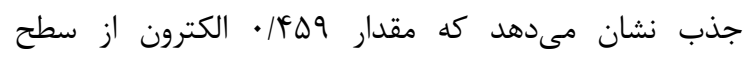

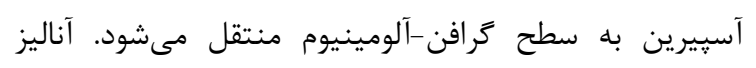

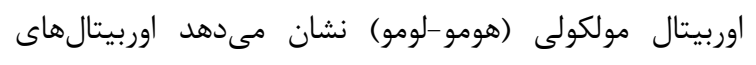

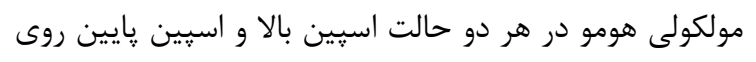

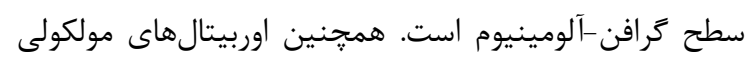

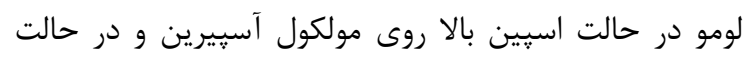
اسيّين پايين بيشتر روى صفحه كرافن قرار مى كيرند.

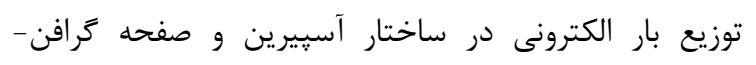

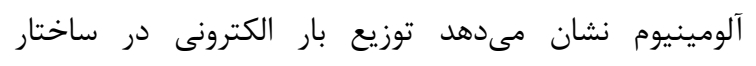

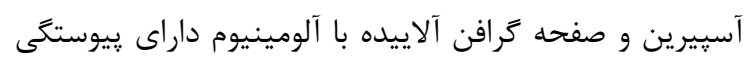

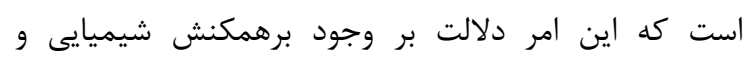

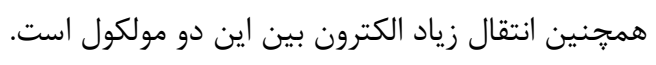

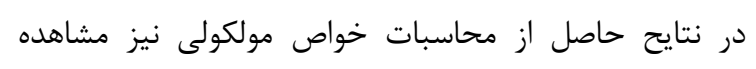

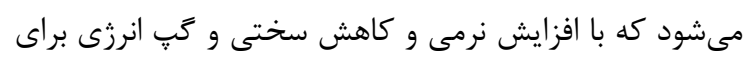

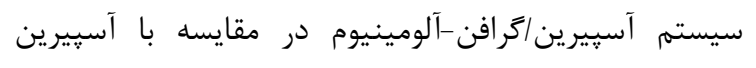

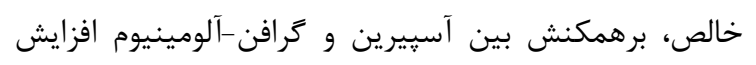

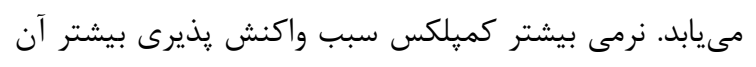

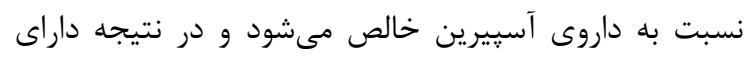

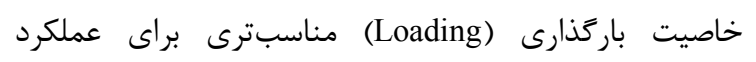
دارويى است.

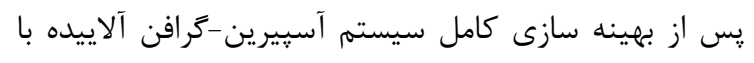

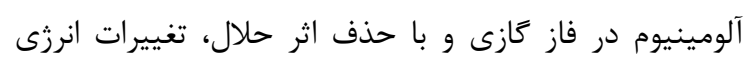

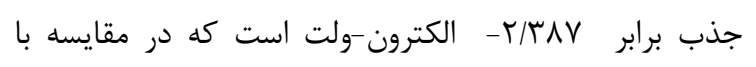

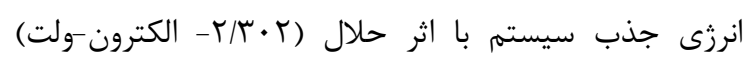

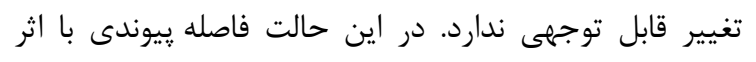

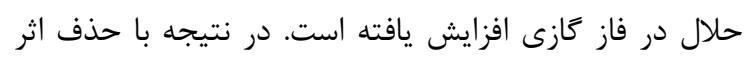

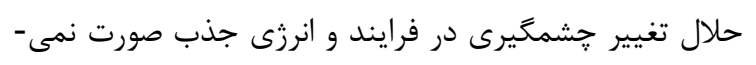
كيرد. در محاسبات انرزى جذب حاصل از حذف نيروهاى واندروالسى

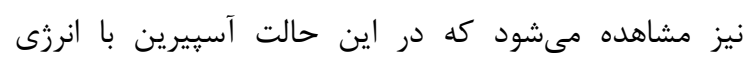

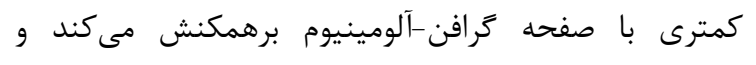

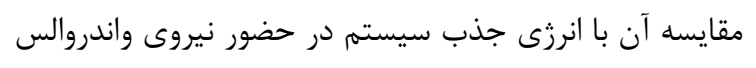

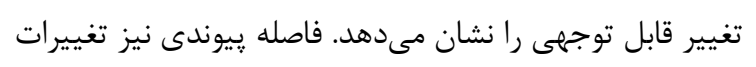

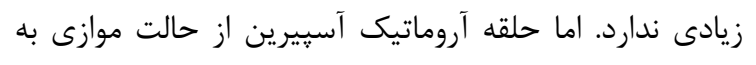

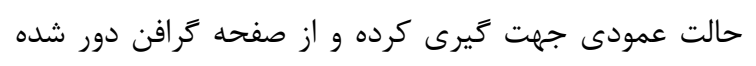

مىدهد واكنش آسيرين با كوارتز يك واكنش شيميايى كرمازا

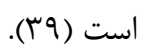

كنجى و همكارانش با استفاده ازمحاسبات تابعى جَّالى،

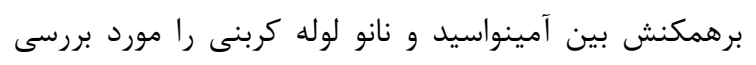

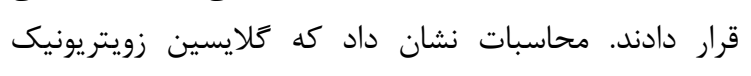

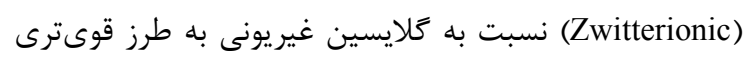

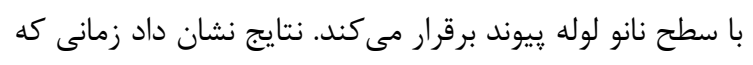

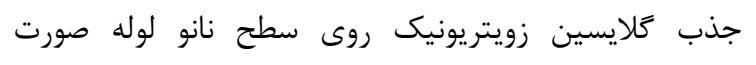

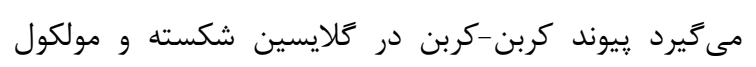

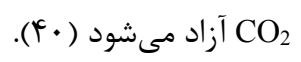

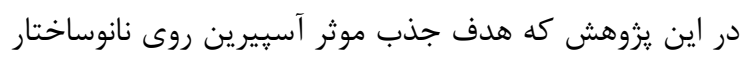

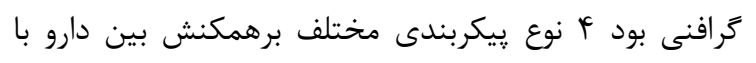

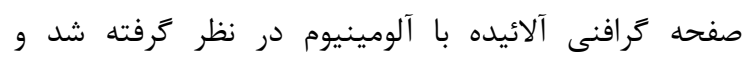

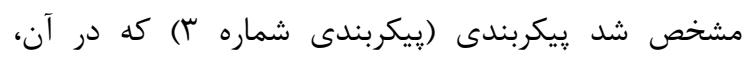

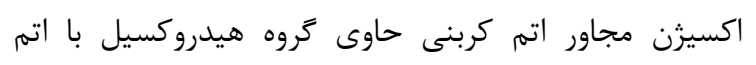

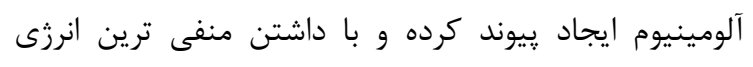
جذب، پايدارترين حالت است. نتايج حاصل از محاسبات انرزى

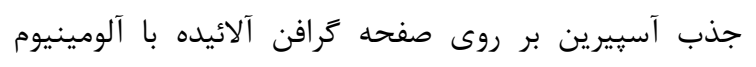

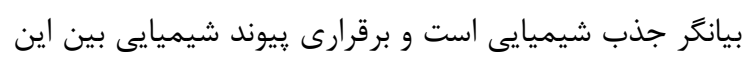

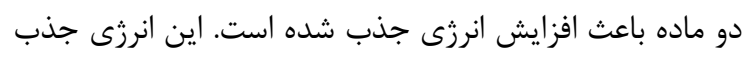

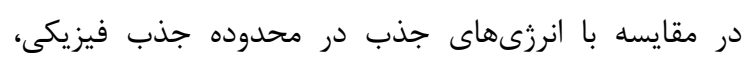

بسيار بيشتر است و از نوع جذب شيميايى به شمار مى آيد.

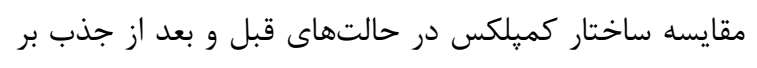

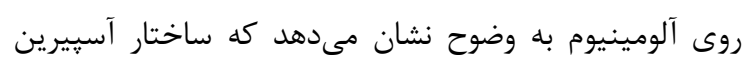

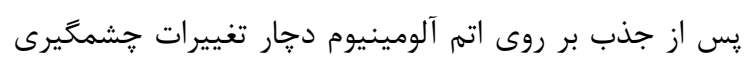

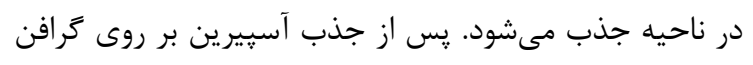

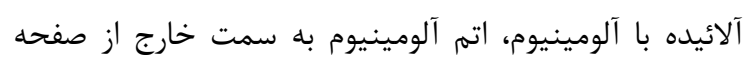

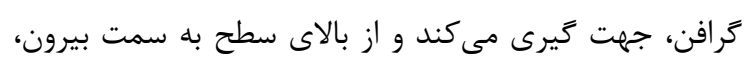

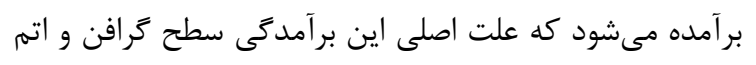

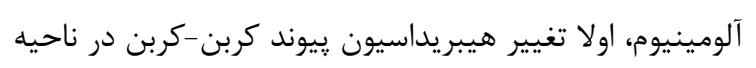

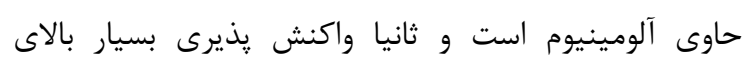

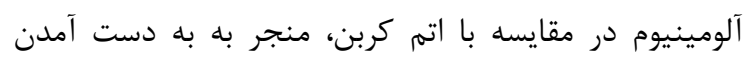
جنين ساختارى مىشود.

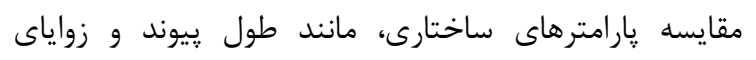

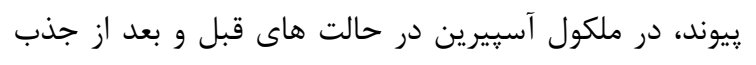

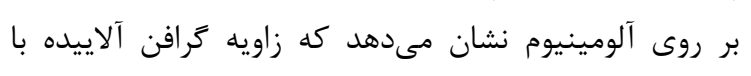
آلومينيوم نسبت به سطح مسطح كرافن تغييرى ندارد.

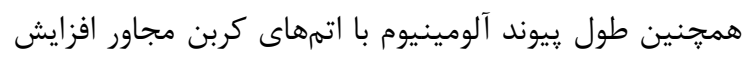

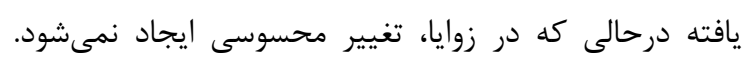

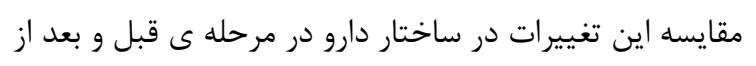




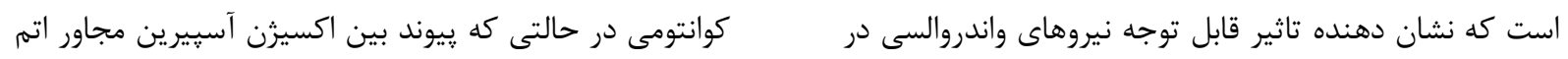

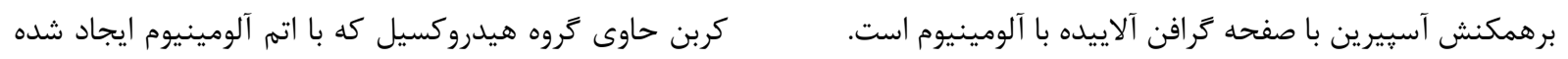

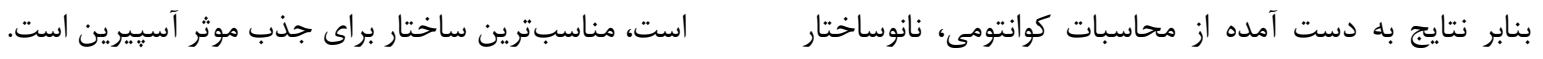

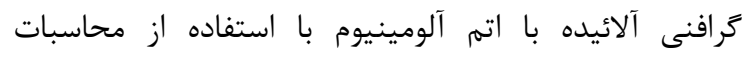

\section{REFERENCES}

1. Shin C, Chase GG, Reneker DH. Recycled expanded polystyrene nanofibers applied in filter media. Colloids Surf 2005;262:211-215.

2. Fan W, Zhang R, Teo BK, Aradi B, Frauenheim T. Prediction of energetically optimal single-walled carbon nanotubes for hydrogen physisorption. Appl Phys Lett 2009;95:013116.

3. Yang W, Moghaddam MJ, Taylor S, Bojarski B, Wieczorek L, Herrmann J, et al. Single-walled carbon nanotubes with DNA recognition. Chem Phys Lett 2007;443:169-72.

4. Mohr S, Pochet P, Amsler M, Schaefer B, Sadeghi A, Genovese L, et al. Boron aggregation in the ground states of boron-carbon fullerenes. Phys Rev B Condens Matter 2014;89:041404.

5. Nicholas R. J, Mainwood A, Eaves L. Introduction. Carbon-based electronics: fundamentals and device applications. Colloids Surf 2007:12; 22-29.

ฯ. Brodie BC. On the atomic weight of graphite. Philosophical Transactions of the Royal Society of London 1859, 149: 249-259.

7. Jahanbani Sh, Benvidi A. A novel electrochemical DNA biosensor based on a modified magnetic bar carbon paste electrode with Fe3O4NPs-reduced graphene oxide/PANHS nanocomposite. Mater Sci Eng 2016, 68: 1-8.

8. Hasanzadeh M, Shadjou N, Mokhtarzadeh A, Ramezani M. Two dimension (2-D) graphene-based nanomaterials as signal amplification elements in electrochemical microfluidic immune-devices: Recent advances. Mater Sci Eng 2016; 68: 482-493.

9. Wu W, Yu B, Wu H, Wang S, Xia Q, Ding Y. Synthesis of tremella-like CoS and its application in sensing of hydrogen peroxide and glucose. Mater Sci Eng 2017; 70: 430-437.

10. Mutyala S, Mathiyarasu J. A reagentless non-enzymatic hydrogen peroxide sensor presented using electrochemically reduced graphene oxide modified glassy carbon electrode. Mater Sci Eng 2016; 69: 398-406.

11. Wang D, Xu F, Hu J, Lin M. Phytic acid/graphene oxide nanocomposites modified electrode for electrochemical sensing of dopamine. Mater Sci Eng 2017; 71: 1086-89.

12. Daneshvar L, Rounaghi G. H, Es' haghi Z, Chamsaz M, Tarahomi S. Fabrication a new modified electrochemical sensor based on $\mathrm{Au}-\mathrm{Pd}$ bimetallic nanoparticle decorated graphene for citalopram determination. Mater Sci Eng 2016; 69: 653-660.

13. Zhang D, Li L, Ma W, Chen X, Zhang Y. Electrodeposited reduced graphene oxide incorporating polymerization of 1-lysine on electrode surface and its application in simultaneous electrochemical determination of ascorbic acid, dopamine and uric acid. Mater Sci Eng 2017; 70: 241-249.

14. Mendes RG, Bachmatiuk A, Büchner B, Cuniberti G, Rümmeli MH. Carbon nanostructures as multi-functional drug delivery platforms. J Mater Chem B 2013; 1: 401-428.

15. Zhu Y, Murali S, Cai W, Li X, Suk JW, Potts JR, et al. Graphene and graphene oxide: synthesis, properties, and applications. Adv Mater 2010; 22: 3906-3924.

16. Zhang Y, Ali SF, Dervishi E, Xu Y, Li Z, Casciano D, et al. Cytotoxicity effects of graphene and single-wall carbon nanotubes in neural phaeochromocytoma-derived PC12 cells. ACS Nano 2010;4:3181-86.

17. Davis ME, Shin DM. Nanoparticle therapeutics: an emerging treatment modality for cancer. Nat Rev Drug Discov 2008;7:771-82.

18. Zhang Q, Wu Z, Li N, Pu Y, Wang B, Zhang T, et al. Advanced review of graphene-based nanomaterials in drug delivery systems: Synthesis, modification, toxicity and application. Mater Sci Eng 2017;12: 48-52.

19. Novoselov KS, Geim AK, Morozov SV, Jiang D, Zhang Y, Dubonos SV, et al. Electric field effect in atomically thin carbon films. Science 2004;306:666-9.

20. Geim AK, Novoselov KS. The rise of graphene. Nat Mater 2007;6:183-91.

21. Cheng TO. The history of aspirin. Tex Heart Inst J 2007; 34: 392-95. 
22. Ferreira SH, Moncada S, Vane JR. Prostaglandins and the mechanism of analgesia produced by aspirin $\square$ like drugs. Br J Pharmacol 197; 49: 86-97.

23. Lewis Jr HD, Davis JW, Archibald DG, Steinke WE, Smitherman TC, Doherty III JE, et al. Protective effects of aspirin against acute myocardial infarction and death in men with unstable angina: results of a Veterans Administration Cooperative Study. N Engl J Med 1983; 309: 396-403.

24. Lee Y, Kwon DG, Kim G, Kwon YK. Ab initio study of aspirin adsorption on single-walled carbon and carbon nitride nanotubes. Phys Chem Chem Phys 2017; 19: 8076-8081.

25. Carstensen JT, Attarchi F, Hou XP. Decomposition of aspirin in the solid state in the presence of limited amounts of moisture. J Pharm Sci 1985; 74: 741-745.

26. Al-Gohary OM, Al-Gamal SS, Hammad A, Molokhia AM. Effect of storage on tabletted microencapsulated aspirin granules. Int J Pharm 1989; 55: 47-52.

27. Baughman RH, Zakhidov AA, De Heer WA. Carbon nanotubes--the route toward applications. Science 2002;297:787-92.

28. Pop E, Mann D, Wang Q, Goodson K, Dai H. Thermal conductance of an individual single-wall carbon nanotube above room temperature. Nano Lett 2006;6:96-100.

29. Delgado JM, Rodes A, Orts JM. B3LYP and in situ ATR-SEIRAS study of the infrared behavior and bonding mode of adsorbed acetate anions on silver thin-film electrodes. J Phys Chem C 2007;111):14476-83.

30. Parr RG. Density functional theory of atoms and molecules. In: Fukui K, Pullman B, Editors. Horizons of quantum chemistry. Dordrecht: Académie Internationale Des Sciences Moléculaires Quantiques / International Academy of Quantum Molecular Science; 1980.

31. Ajima K, Yudasaka M, Murakami T, Maigné A, Shiba K, Iijima S. Carbon nanohorns as anticancer drug carriers. Mol Pharm 2005; 2: 475-480.

32. Hohenberg P, Kohn W. Inhomogeneous electron gas. Phys Rev 1964;136:B864.

33. Thorsten $\mathrm{S}$, Rudolf $\mathrm{J}$. How relevant are $\mathrm{S}=\mathrm{O}$ and $\mathrm{P}=\mathrm{O}$ double bonds for the description of the acid molecules $\mathrm{H} 2$ SO 3, H 2 SO 4, and H 3 PO 4, respectively. Mol Mod Ann 2000;6:282-288.

34. Pearson, Ralph G, Jon Songstad. "Application of the principle of hard and soft acids and bases to organic chemistry." J Am Chem Soc 1967; 89: 1827-36.

35. Pearson RG. The principle of maximum hardness. Acc Chem Res 1993; 26: 250-255.

36. Abbasi A, Jahanbin Sardroodi J. A First-principles study of the interaction of aspirin with nitrogen-doped TiO2 anatase nanoparticles. Nanomed Res J 2016;1:69-78.

37. Vessally E, Esrafili MD, Nurazar R, Nematollahi P, Bekhradnia A. A DFT study on electronic and optical properties of aspirin-functionalized B12N12 fullerene-like nanocluster. Str Chem 2017;28:735-48.

38. Datt A, Fields D, Larsen SC. An experimental and computational study of the loading and release of aspirin from zeolite HY. J Phys Chem C 2012;116:21382-90.

39. Abbasi A, Nadimi E, Plänitz P, Radehaus C. Density functional study of the adsorption of aspirin on the hydroxylated (001) $\alpha$-quartz surface. Science 2009;603:2502-6.

40. Ganji M. Density functional theory based treatment of amino acids adsorption on single-walled carbon nanotubes. Diam Relat Mater 2009;18:662-8. 